\title{
Quantitative Weathering Assessment of Rock Slope using CIELAB Color Space and Image Analysis Technique
}

\author{
Mazlina Razali \\ Universiti Sains Malaysia \\ Muhd Herman Jamal \\ Universiti Sains Malaysia
}

Mohd Ashraf Mohamad Ismail ( $\square$ ceashraf@usm.my )

Universiti Sains Malaysia https://orcid.org/0000-0002-7105-4992

Intan Norsheira Yusoff

Universiti Sains Malaysia

Sharan Kumar Nagendran

Centre of Excellence for Engineering and Technology (CREaTE)

\section{Zuraini Zainal}

Centre of Excellence for Engineering and Technology (CREaTE)

Nurul Eilmy Zainuddin

Centre of Excellence for Engineering and Technology (CREaTE)

Hayato Tobe

Kajima Corporation

Takako Miyoshi

Kajima Corporation

Kensuke Date

Kajima Technical Research Institute Singapore

Yasuhiro Yokota

Kajima Technical Research Institute Singapore

\section{Research Article}

Keywords: rock slope, granitic slope surface, slope stability assessment, image analysis, CIELAB

Posted Date: October 29th, 2021

DOl: https://doi.org/10.21203/rs.3.rs-937366/v1 
License: (c) (i) This work is licensed under a Creative Commons Attribution 4.0 International License. Read Full License 


\title{
Quantitative Weathering Assessment of Rock Slope using CIELAB Color Space and Image Analysis Technique
}

\author{
Mazlina Razali ${ }^{1,3}$ (D) Muhd Herman Jamal ${ }^{1}$, Mohd Ashraf Mohamad Ismail ${ }^{2 *}$, Intan \\ Norsheira Yusoff $^{1}$, Sharan Kumar Nagendran ${ }^{4}$, Zuraini Zainal ${ }^{4}$, Nurul Eilmy Zainuddin ${ }^{4}$, \\ Hayato Tobe $^{5}$, Takako Miyoshi ${ }^{5}$, Kensuke Date $^{6}$ and Yasuhiro Yokota ${ }^{6}$ \\ ${ }^{I}$ School of Civil Engineering, Engineering Campus, Universiti Sains Malaysia, Penang, Malaysia \\ ${ }^{2 *}$ School of Civil Engineering, Engineering Campus, Universiti Sains Malaysia, Penang, Malaysia \\ ${ }^{3}$ School of Civil Engineering, College of Engineering, Universiti Teknologi MARA, Cawangan Pulau \\ Pinang, Kampus Permatang Pauh, Penang, Malaysia \\ ${ }^{4}$ Centre of Excellence for Engineering and Technology (CREaTE), Public Works Department (JKR), \\ Alor Gajah, Melaka, Malaysia \\ ${ }^{5}$ Rock Mechanics and Hydro-geology Group, Kajima Technical Research Institute, Kajima \\ Corporation \\ ${ }^{6}$ Kajima Technical Research Institute Singapore, Kajima Corporation \\ *Corresponding author(s).E-mail(s): ceashraf@usm.my
}

\begin{abstract}
Quantitative weathering assessment using color changes is one of the new tools for slope stability assessment. In many other engineering field, CIELAB color space and image analytical tools have aided in enhancing the conventional method or inaccuracy due to the subjective and qualitative nature of visual assessment. This study focuses on the granitic rock slope surface assessment because of the predominant rock formation of granite in Malaysia. The 3D model of the rock slope was analyzed to extract the geological planes using compass plugin in Cloud Compare software and verified by manual compass mapping via scanline survey. Findings show that the $a^{*}$ and $b^{*}$ values increased with an increase in weathering results. This study focuses on the 50 points of measurement of rock slope and indicated a positive correlation of $\mathrm{a}^{*}$ and $\mathrm{b}^{*}$ with $\mathrm{R} 2=0.9027$. The image analysis result of the rock slope shows that major zoning (74\%) is susceptible to failure due to structural control whilst another $26 \%$ are controlled by significant weathering in the grade IV-VI. This outcomes is strongly verified via a geomechanical test, geological structure, and mineralogical assessment. The aforementioned mechanism is recommended in any geotechnical and technical purpose in enhancing the method of weathering assessment because image analysis provides reliable measurements in addition to the manual visual inspection.
\end{abstract}

Keywords: rock slope, granitic slope surface, slope stability assessment, image analysis, CIELAB

\section{Introduction}

Nowadays, quantitative weathering assessment of a rock slope is an important part of engineering geological studys and is used as a tool in slope stability assessments (Abad et al., 2015; Borrelli et al., 2016; Luo et al., 2020). Changes in the color of the rock slope surface may reflect physical and chemical weathering processes (Moses et al., 2014). Geotechnical engineers must estimate a weathering grade, quantify the changes that occur during weathering, and classify the weathered rocks zone. In recent years, image analysis techniques from drone images emphasize the weathering impacts over rock slope instability assessment (Kim et al., 2018; Ye et al., 2020). Weathering assessment is frequently based on qualitative or subjective visual inspections, the results of which will most likely vary from person to person (Tobe et al., 2018). This problem was encountered by quantitatively measuring the color of the rock 
surface using CIELAB color space and utilizing an image processing method (Tobe et al., 2018). A colorimeter is a device used to determine the color of the weathered rock surfaces. Geological structural and geomechanical testing, such as in situ Schmidt hammer, uniaxial compression strength, ultrasonic pulse wave test, and mineralogy, were used to validate the results. In this study, the digital image analysis reliability was enhanced by using the CIELAB color space to filter or convert the 2D orthophoto images of the rock slope color surface to different weathering grade regions. The filtered or categorized area of the weathering grades, together with other geomechanical inputs, geological structure, and mineralogical assessment, is to indicate the slope's vulnerability. In this study, Compass plugin in CloudCompare is used to extract discontinuity orientations for geological structure and verified by manual compass mapping (Garcia-Luna et al., 2019; Nagendran et al., 2019b). Unmanned Aerial Vehicle (UAV) photogrammetry have been used in this study to create 3D surface models and generate pointcloud information of the rock slope surface. The high-resolution data generated by image analysis using a variety of analytical tools may reveal the detailed geological structure of the rock surfaces and weathering assessment (Kim et al., 2018; Kong et al., 2021; Nagendran et al., 2019a; Salvini et al., 2020; Zekkos et al., 2018). The primary goal of this study is to develop a quick preliminary method based on a quantitative weathering assessment that uses CIELAB color space and image analysis to detect the weathering characteristics of the rock mass and calculate the weathering degree based on the percentages of weathered zones. These methods would provide a simple and cost-effective method for quantifying the relative weathering of rock mass in tropical climatic conditions.

\subsection{Geological Background}

In this study, the weathered granitic rock slope was chosen on the basis of its predominant rock formation in the Malaysian Peninsula. The Lebuhraya Kuala Kubu Bharu-Teranum-Raub is composed of granite of the S variety (Fig. 1). The granites of the Main Range are typically coarsely porphyritic with perthitic to microcline alkali feldspar (Jasin, 2013; Jasin \& Harun, 2011a; Spiller, 2002). The S-type Main Range Granite (granitoid belt) is found along the western margin of the Bentong-Raub suture zone, although it occasionally intrudes into the suture zone, forming a stitching pluton (Jasin, 2013; Jasin \& Harun, 2011b; Metcalfe, 2000, 2013). The rock slope latitude is $3^{\circ} 33^{\prime} 57.23^{\prime \prime} \mathrm{N}$, and the longitude is $101^{\circ} 42^{\prime} 34.97^{\prime \prime} \mathrm{E}$. The rock slope's perimeters reach $102 \mathrm{~m}$, and the crest's elevation is $327 \mathrm{~m}$. 


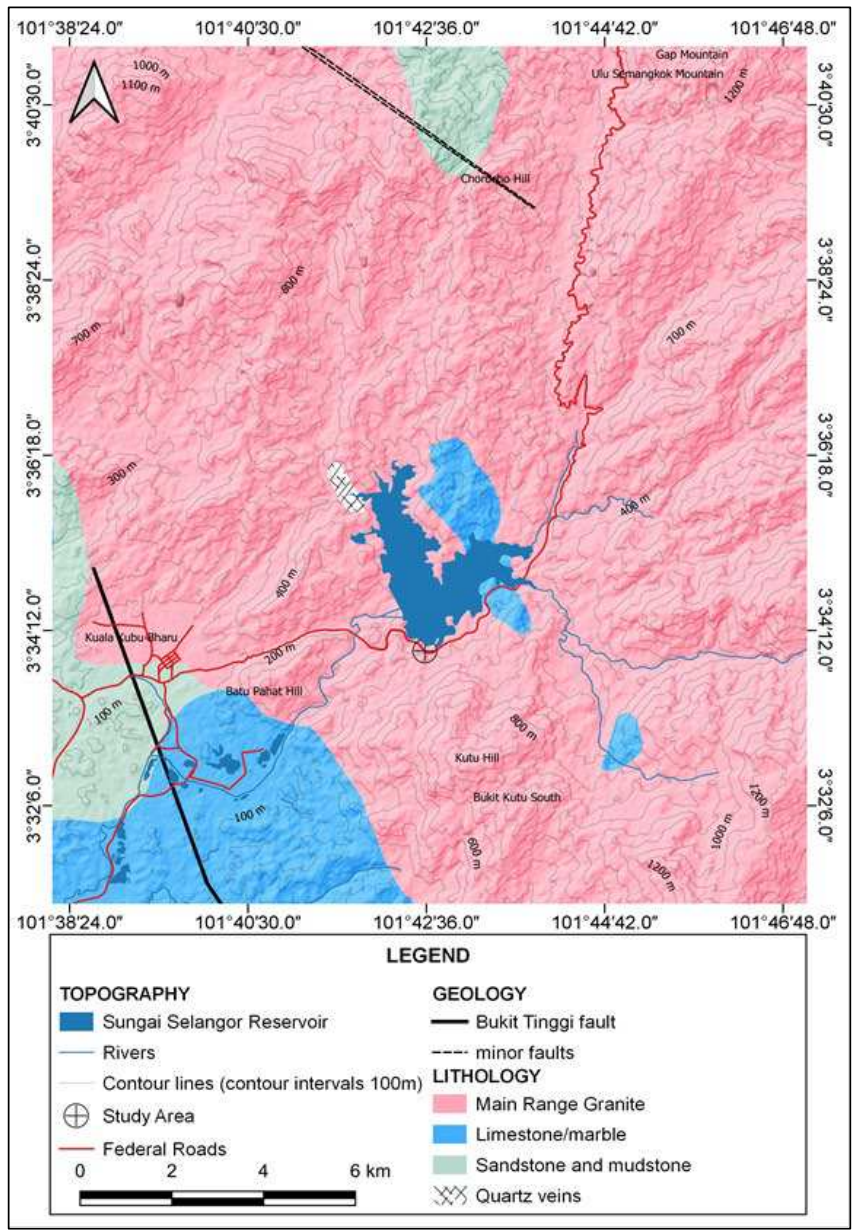

Fig. 1 General geology of the study area (Lebuhraya Kuala Kubu Bharu-Teranum-Raub route). Modified after the map provided by Jabatan Mineralogi dan Geosains 2014. Map Scale 1:10000

\subsection{Weathering Assessment}

The weathered rock surfaces may possess different colors because of the random chemical reactions occurring on the surface. Gokay (2018) reported that volcanic eruption from magma has its mineral composition, which results in a variety of colored rock masses. When assessing rock weathering effects on a selected surface, the primary distinguishing factors include rock surface color. Most rock weathering has altered the mechanical and chemical characteristics of the rock mass (Bobina \& Abaturova, 2020; Borrelli et al., 2016; Ghiasi et al., 2009; Park \& Kim, 2019). Under humid tropical circumstances, weathering of granite results in microstructural changes, such as discoloration, microfracturing, and loosening of grain boundaries (Tan et al., 2016; Tobe et al., 2018). The weathering mechanism in Fig. 2 shows the color changes from the granitic slope surface and the attack to the inside of the cracks (Thuro et al., 2002). Given the visible color changes, a weathering assessment must be conducted to determine whether the rock slope is slightly weathered, heavily weathered, or structurally failed. In Fig. 3 the visible physical and chemical weathering on the granite slope indicates the presence of iron staining on the surface (Grotzinger et al., 2009). Both weathering processes take place in conjunction with the joint runoff. Unweathered granite contains sodium plagioclase feldspar ( $\mathrm{Na}$ feldspar), potassium feldspar (K feldspar), quartz, biotite, amphibole, and muscovite. Weathered granite will affect the hydrolysis of $\mathrm{Na}$ and $\mathrm{K}$ feldspar to form kaolinite (clay) and $\mathrm{Na}+$ and $\mathrm{K}+$ ions. Quartz (and, if present, muscovite) are left as residual 
minerals due to their high weathering resistance. Hydrolysis of biotite and/or amphibole yields clay, which is then oxidized to yield iron oxides. Furthermore, moderate-scaled oxidation and hydrolysis (Fig. 3) occurred in the decayed and discolored granite surface. A summary of granite oxidation is provided below:

$$
2 \mathrm{FeS}_{2}+7 \mathrm{O}_{2}+2 \mathrm{H}_{2} \mathrm{O} \rightarrow 2 \mathrm{FeSO}_{4} \text { (black color) }+2 \mathrm{H}_{2} \mathrm{SO}_{4} \text { (sulfuric acid) }
$$

The hydrolysis in granite also occurs when feldspar in the granite body reacts with the carbonic acid and water from the rain and subsequently produces kaolinite as the product. The reaction is as follows:

$$
2 \mathrm{KAlSi} 3 \mathrm{O} 8+2 \mathrm{H}_{2} \mathrm{CO}_{3}+9 \mathrm{H}_{2} \mathrm{O} \rightarrow \mathrm{Al}_{2} \mathrm{Si}_{2} \mathrm{O}_{5}(\mathrm{OH})_{4}+4 \mathrm{H}_{4} \mathrm{SiO}_{4}+2 \mathrm{~K}++2 \mathrm{HCO}_{3}-
$$

The biological weathering in this study is quite visible when the minimal vegetation grows along the seepage or runoff and in-between berms. The black mould covers many parts of the slope.

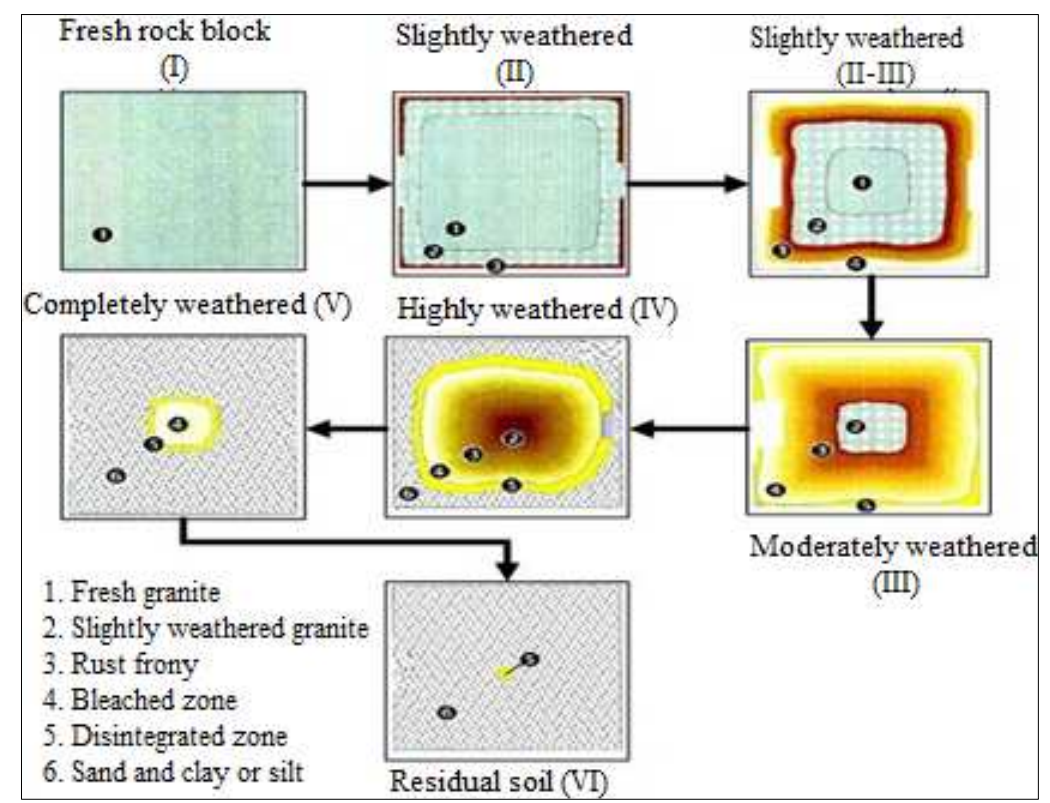

Fig. 2 Distribution of weathering grade of the rock mass (Thuro et al., 2002)

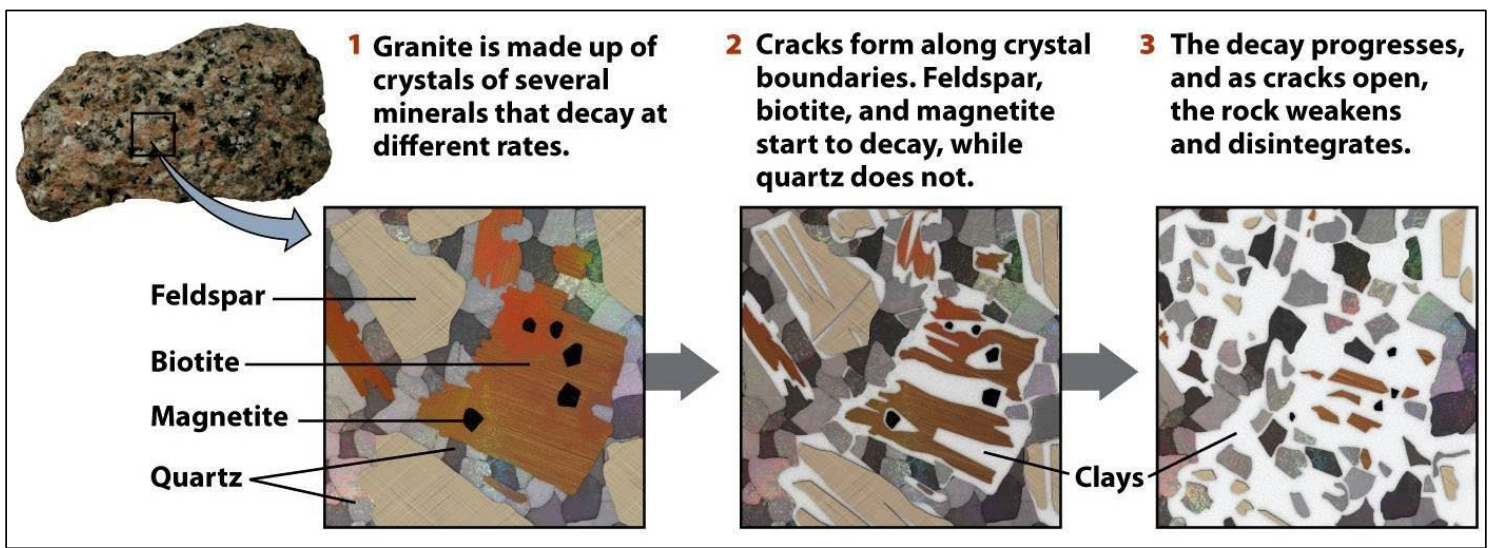

Fig. 3 Chemical weathering process of granite (Grotzinger et al., 2009) 


\section{Cielab Color Space}

\subsection{General Concept}

This study explores the CIELAB color space analysis in examining the effects of different color systems based on Richard Hunter's former L, a, and b systems (Cinko \& Becerir, 2019; Goyena $\&$ Fallis, 2019; Shrivastava et al., 2021; Thwaites et al., 2018; Yeerken, 2017). This framework is the most widely used color management system because it implements the international color consortium's (ICC) device profile in a device-independent model. L*a*b* is an abbreviation for the three distinct color spaces (Cinko \& Becerir, 2019). RGB images were transformed to CIELAB (Cinko \& Becerir, 2019; ju et al., 2014; Shrivastava et al., 2021; Thwaites et al., 2018; Yeerken, 2017). CIELAB is a nonlinear transformation of RGB in which the Euclidean distance between two colors equals the perceived distance between them (for distances $<10$ units). Color image processing algorithms frequently provide excellent performance with CIELAB (Ju et al., 2014). When a color is stated in CIELAB (Fig. 4), the term L* refers to the image's luminance or brightness. The values are between $[0,100]$, where zero indicates black, and 100 indicates white. The colors get brighter with the increase in $L^{*}(\mathrm{Kim}, 2015)$. The value of $\mathrm{a}^{*}$ indicates the proportion of red or green tones in the picture. A massively positive $\mathrm{a}^{*}$ value indicates the presence of red/magenta. Green is represented by a large negative $a^{*}$ value. Although there is no fixed range for $a^{*}$, the values often lie between $[-100,100]$, whereas $b^{*}$ specifies the amount of yellow or blue tones in the picture. Yellow is represented by a large positive $b^{*}$ value. A significant negative $b^{*}$ value correlates to the color blue. Although there is no fixed range for $b^{*}$, the values often lie between $[-100,100]$ according to CIE 1976 (Cinko $\&$ Becerir, 2019; Grad et al., 2013; Yeerken, 2017). The colors with "+" values (red and yellow) are considered "hot", while those with "-"values (green and blue) are regarded as "cold". Many weathered earth materials have "hot colors", making the L*a*b parameter suitable for quantitative evaluation. The center of each axis is zero. $a^{*}$ and $b^{*}$ with a value of zero, or very low, will describe a neutral or near neutral. The area around the center represents achromatic colors, and color saturation increases as move outside from the center (Fig. 4).

CIELAB and $\triangle E a b$ Eq.(1) were introduced by the International Commission on Illumination (CIE) in 1976 (Eq. 1) and were documented in ISO 11664-4:2008 | CIE S 0144:2007 (ISO/CIE 11664-4:2019; Ohta \& Robertson, 2005). There is a lack of consistency if a different color is compared (Gokay, 2018; D. H. Kim et al., 2018; Mahyar \& Cheung, 2007; Rostami et al., 2015; Westland et al., 2013; Yeerken, 2017).

$$
\text { Color difference, } \Delta \mathrm{E}_{\mathrm{ab}}^{*}=\sqrt{\left(\mathrm{L}_{2}^{*}-\mathrm{L}_{1}^{*}\right)^{2}+\left(\mathrm{a}_{2}^{*}-\mathrm{a}_{1}^{*}\right)^{2}+\left(\mathrm{b}_{2}^{*}-\mathrm{b}_{1}^{*}\right)^{2}} \text {, }
$$

where $\triangle \boldsymbol{E}_{\boldsymbol{a} \boldsymbol{b}}^{*}$ is a total color difference, $\mathrm{L}^{*}$ is lightness, a ${ }^{*}$ is red/green, and $\mathrm{b}^{*}$ is yellow/blue (Fig. 4).

In this study, perceived color distance is used in a simple and effective approach to improve the quality of full-reference image algorithms. The perceived color distance is calculated using the difference between colors in the CIELAB color space (Cinko \& Becerir, 2019; Lovisolo, 2011; Roy Choudhury, 2015a)(Lovisolo, 2011; Roy Choudhury, 2015). The formula for the color difference is a critical tool for industrial color quality management. Since 1976, when the CIE suggested the CIELAB1 and CIELUV1 color spaces for unifying practice, different color-difference equations based on CIELAB have been created (Coloration \& Kim, 2015; D. H. Kim, 2015). 


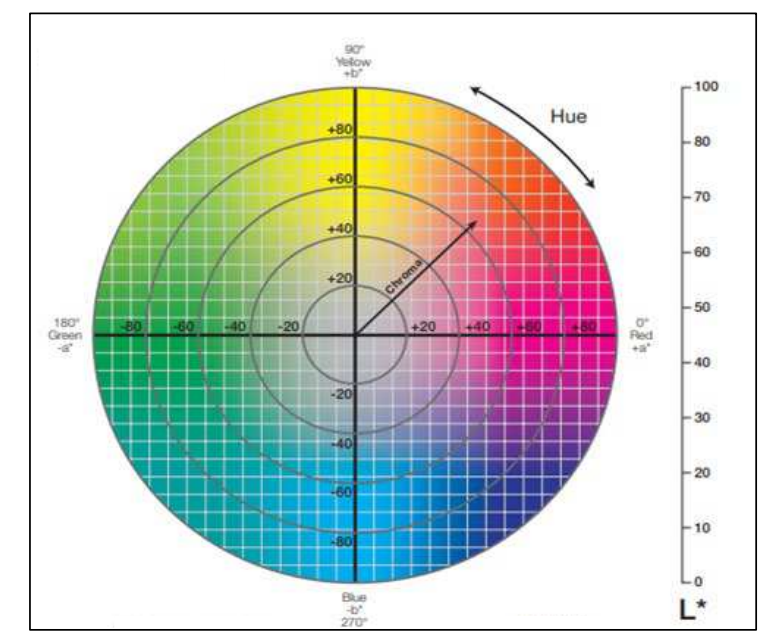

Fig. 4 Theoretical CIELAB color space (Hunter, 1958)

The plot of $a^{*}$ and $b^{*}$ on the color space shows the apple's chromaticity, while the $\mathrm{L}^{*}$ expresses the color's lightness (Fig.5). The $\mathrm{L}^{*} \mathrm{a}^{*} \mathrm{~b}^{*}$ color space enables precise color communication between a company and its supply chain, ensuring that products are manufactured to exact color specifications. Color difference $\Delta$ Eab calculated from the L*a*b* values of a master and sample provides an easy quality check. The method used in this study for weathering assessment of rock slope with a colorimeter is similar to the mechanism utilized to measure the apple (Fig. 6). The color on the surface of the rock slope represents the degree of weathering. High $\mathrm{a}^{*}$ and $\mathrm{b}^{*}$ values indicate that the rock is more weathered and provides a good weathering assessment. The following values (Fig. 6) show that heavily weathered samples had higher $a^{*}$ and $b^{*}$ values than unweathered ones.

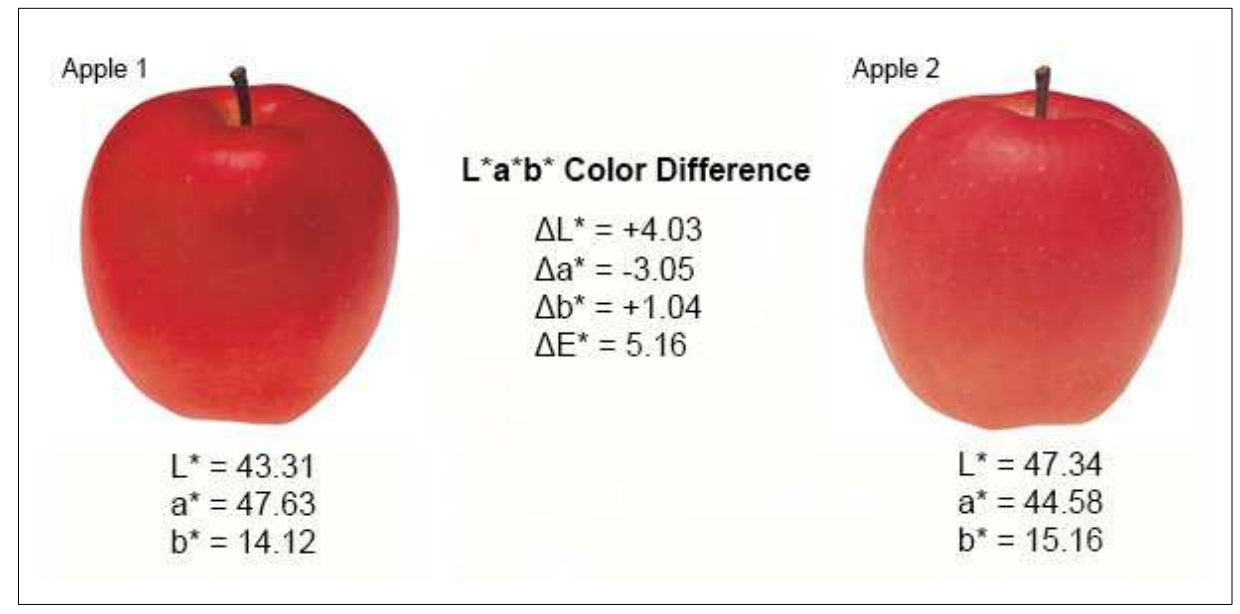

Fig. $5 \mathrm{~L}^{*}$, $\mathrm{a}^{*}$, and $\mathrm{b}^{*}$ color difference from the spectrophotometer 


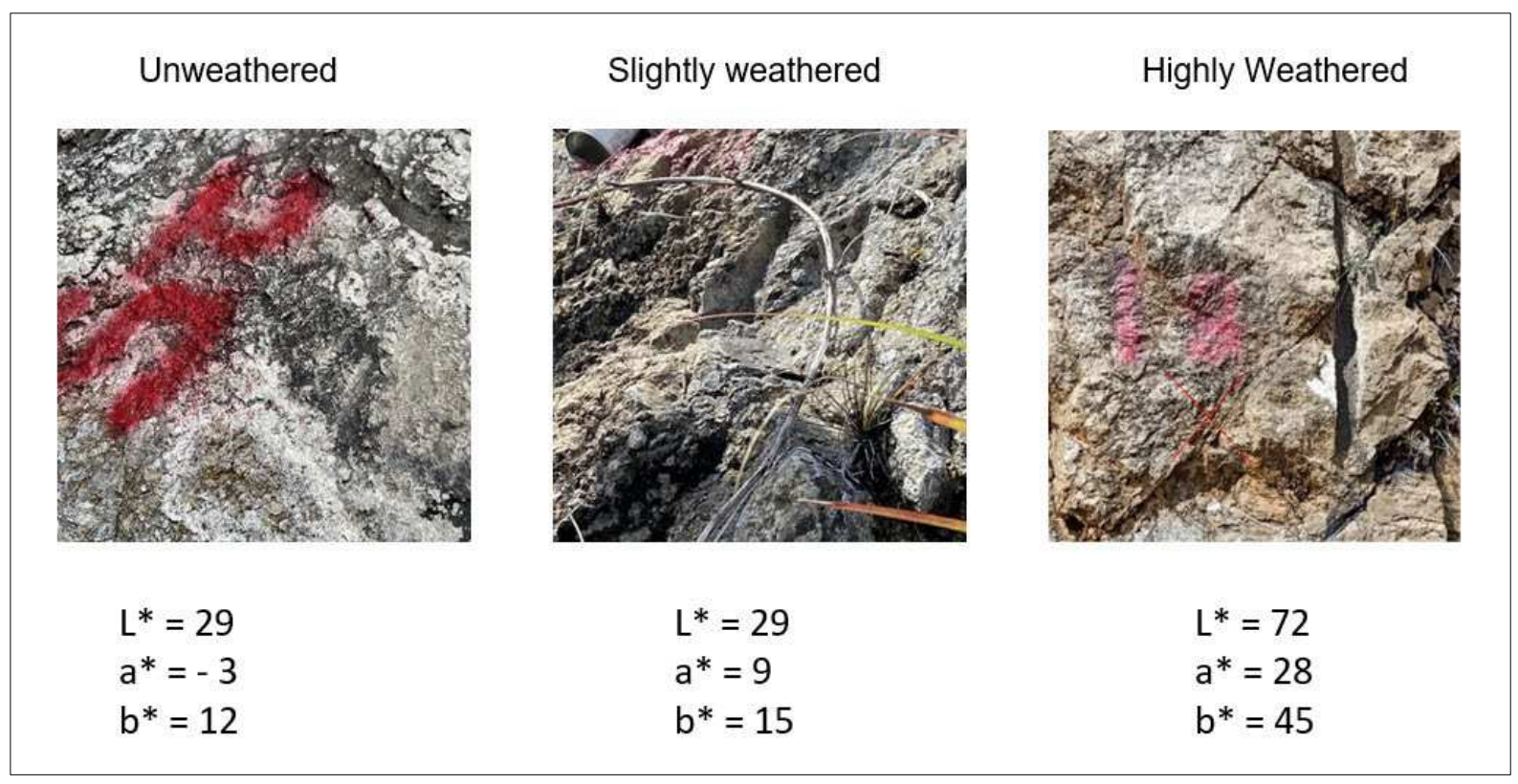

Fig. 6 Color analysis of the different weathering grades from the rock mass sample

\subsection{Colorimeter Test}

In this study, a colorimeter is a tool to assess the rock slope surface weathering color. In the in situ colorimeter test, red, green, and blue light sources were used to illuminate the rock slope surface. Tri-stimulus (RGB) values are distilled using these filters to match how our eyes perceive color (Amano et al., 2020; Ohta \& Robertson, 2005; Planetary \& Congress, 2014). When electromagnetic radiation is transmitted or reflected through an object or solution, the intensity of the electromagnetic radiation varies. The FRU Colorimeter WR18 with a $40 \mathrm{~mm}$ aperture was used for this study because it can measure big textured, uneven, and rough surfaces (Fig. 7) (Tobe et al., 2018). Kemp (2014) conducted a similar method by using a colorimetric analysis to measure the $\mathrm{L}^{*}, \mathrm{a}^{*}$, and $\mathrm{b}^{*}$ values of the rock slope. In this study, the different surface colors were tested for the value of $\mathrm{a}^{*}$ and $\mathrm{b}^{*}$ at 50 points of measurement, as shown in the orthophoto image (Fig. 9). Colorimeters must be calibrated with computer monitors to ensure accurate screen colors. Color software is used to import colorimeter data, which are then used as input data for image analysis.
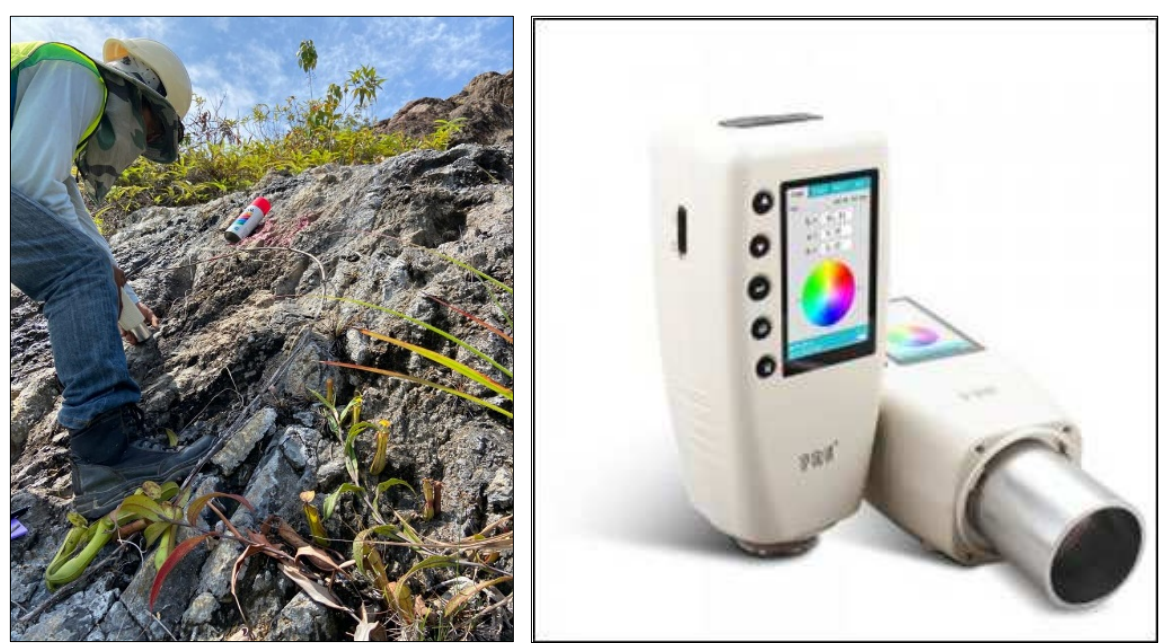

Fig. 7 In situ colorimeter testing using FRU colorimeter WR18 (40 mm aperture) 


\section{Uav Photogrammetry Utilization}

\subsection{Field Data Acquisition}

Field data for UAV photogrammetry were collected with the DJI Phantom 4 Pro Version Quadcopter with DJI-FC6310 sensor and a 20 MP camera. Table 1 summarizes the mapping parameters in details.

Table 1 Summary of the mapping details

\begin{tabular}{|c|c|c|}
\hline Description & Classification & \\
\hline Sensor(s) used & DJI-FC6310 & \\
\hline Image resolution & $5472 \times 3648(\sim 20 \mathrm{MP})$ & \\
\hline Orthomosaic coverage ( $\%$ of the area of interest) & 108.90 & \\
\hline $\begin{array}{l}\text { Average orthomosaic image density within a } \\
\text { structured area }\end{array}$ & 34 images/pixel & \\
\hline Median shutter speed & $1 / 320$ & \\
\hline Aligned cameras & $99 \%(478 / 482)$ & \\
\hline RMSE of the camera GPS location & $\begin{array}{l}\text { X } 1.54 \mathrm{ft} \quad \mathrm{Y} 1.86 \mathrm{ft} \\
\mathrm{ftRMSE} 1.74 \mathrm{ft}\end{array}$ & Z 1.79 \\
\hline
\end{tabular}

\subsection{Processing UAV Imagery Datasets}

Agisoft Metashape Professional (version 1.7.0) software is utilized in processing the georeferenced photos collected by the UAV (Agisoft \& St Petersburg, 2016). The approach begins with the import and the alignment of UAV images with a high precision setting (Fig. 8). During the alignment of the image, it matches the scale-invariant using the transform (SIFT) technique and undergoes bundle block adjustments. The SIFT algorithm distinguishes and characterizes local features in the imagery (de Matias et al., 2009). It locates important spots and furnishes them with quantitative methods that the descriptors will utilize for object recognition. Then, the image information is transformed into local feature coordinates that are invariant to translation, rotation, scale, and other imaging parameters. Dense geometry is reconstructed with a high degree of accuracy, and 59 million points are generated as a 3D dense point cloud. Further processing of the dense cloud results in the creation of a digital surface model and orthoimages (Fig. 9). 


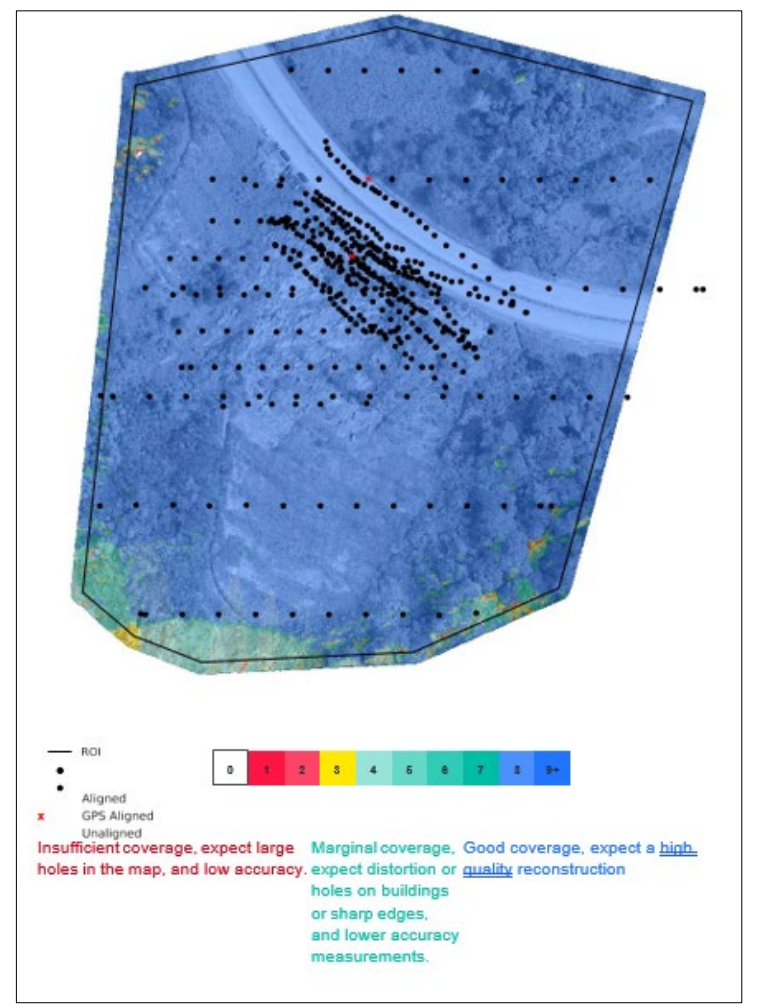

Fig. 8 Camera positions and the aligned images for rock slope at Lebuhraya Kuala Kubu Bharu-Teranum-Raub

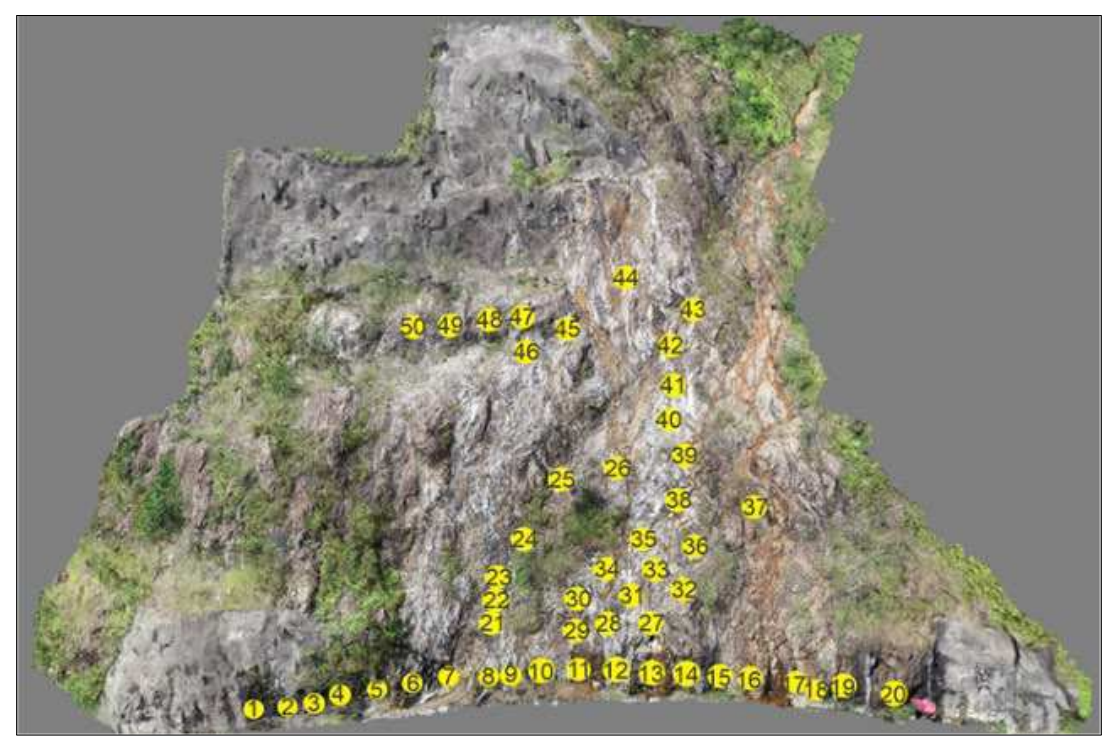

Fig. 9 Orthophoto of Lebuhraya Kubu Bharu-Teranum-Raub with 50 points of measurement marking

\section{$4 \quad$ Image Analysis}

Image analysis is one of the methods used in this study to improve conventional weathering assessment. This study is conducted in response to the need to analyze the slope surface using JudGeo Software as illustrated in the workflow in Fig. 10 (Tobe et al., 2018, 2020). The laboratory data produced from the colorimeter served as a reference and range for obtaining the best result to carry out the weathering assessment quantitatively. Each color shown in the 
image analysis represents the weathering grade for the rock slope surface. Similar work has also been carried in which defining geological features from images and characteristics can be automatically recorded and reconstructed using a digital processing technique (Buyer et al., 2018; Chen et al., 2020; Kim et al., 2018; Mohan \& Poobal, 2018; Mohebbi et al., 2017; Tobe et al., 2018, 2020).

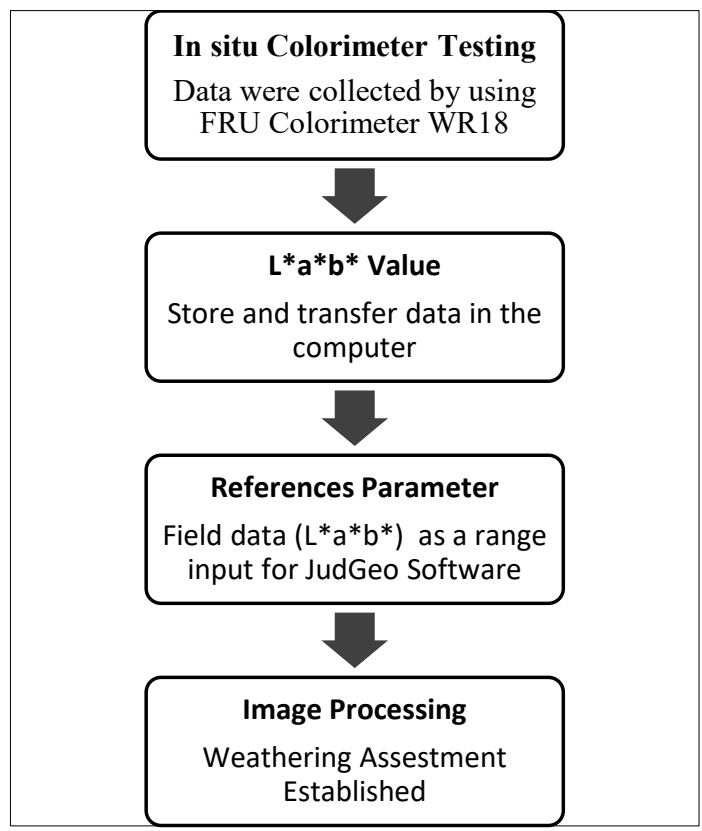

Fig. 10 Image processing framework in JudGeo software (Tobe et al., 2018)

The reliability of the digital image analysis was increased in this study by filtering or converting the 2D orthophoto images (Fig. 9) of the rock slope color surface to different weathering grade regions utilizing the CIELAB equal color space ( Fig. 11) (Gokay, 2018; Outal et al., 2008; Sun et al., 2019). The filtered or classified region of the weathering grades was utilized in verification with other geomechanical inputs and geological structure to determine the potential failure. However, precautions should be taken in evaluating the image analysis results considering the direction of the discontinuities and another index/mechanical attribute of the rock mass (Roy Choudhury, 2015b). This method was found to be more unbiased compared with the conventional weathering grade zoning. Digital camera images must be converted to $\mathrm{L}^{*} \mathrm{a}{ }^{*} \mathrm{~b}^{*}$ values to accurately evaluate color tones using this method. This goal can be easily accomplished by utilizing existing image processing software. However, this task requires complicated operations. This system is based on equations Eq. (2) to Eq. (6) and automates the process to reduce the number of operations required in the field (Tobe et al., 2020).

$$
\begin{gathered}
r=R / 255, g=G / 255, b=B / 255, \\
\left(\begin{array}{l}
x \\
y \\
z
\end{array}\right)=\left(\begin{array}{lll}
0.3933 & 0.3651 & 0.1903 \\
0.2133 & 0.7010 & 0.0858 \\
0.0182 & 0.11170 & 0.9570
\end{array}\right)\left(\begin{array}{l}
r^{2} \\
g^{2} \\
b^{2}
\end{array}\right), \\
L^{*}=116\left(\frac{\mathrm{y}}{100}\right)^{-\frac{1}{3}}-16, \\
a^{*}=500\left\{\left((x / 95.045)^{-1 / 3}\right)-\left((y / 100)^{-1 / 3}\right)\right\},
\end{gathered}
$$




$$
b^{*}=200\left\{\left((y / 100)^{-1 / 3}\right)-\left((z / 100.892)^{-1 / 3}\right)\right\}
$$

where $R, G$, and $B$ are the luminance of the three primary colors (0-255); $r, g$, and $b$ are the luminance of the three primary colors $(0-1) ; x, y$, and $z$ are conversion values; $\mathrm{L}^{*}$ is lightness; $\mathrm{a}^{*}$ is redness; and $\mathrm{b}^{*}$ is yellowness.

The system convert RGB values to $\mathrm{L}^{*} \mathrm{a} * \mathrm{~b} *$ ones in each pixel and assign pixels to weathering grades to the highly weathered (Fig. 11). The degree of weathering on the slope surface is contoured by setting the color of the heavily weathered sample to no. 5 and the unweathered sample to no. 1 . The areas of the diagram corresponding to no. 3 and higher are referred to as the "weathering region" (green, yellow, and red areas in Fig. 11). The system automatically calculates the proportion of these regions to the entire slope surface, and the value of the proportion is displayed as the slope surface's degree of weathering.ranging five levels of weathering grades from unweathered.

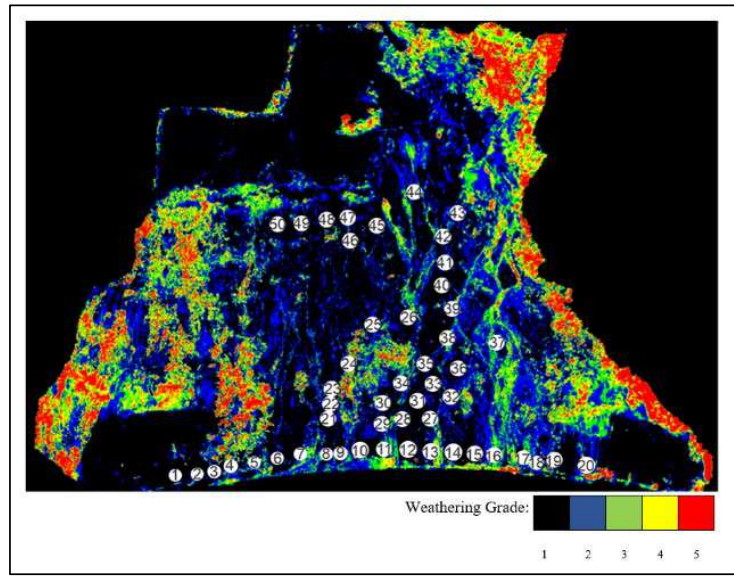

Fig. 11 Weathering evaluation for the rock slope surface by using the image analysis technique

\section{Geological Structural Assessment}

The Compass tool from CloudCompare is used in this study to determine the structural geology of rocks. The 3D point cloud is transferred as input data to CloudCompare software, allowing the Compass tool to extract geological planes for the assessment of rock mass discontinuities (Dewez et al., 2016; Tung et al., 2018; Villarreal J et al., 2020). The dip and dip direction values generated by the software are compared with manual mapping (scan line survey method) (Nagendran et al., 2019a, 2019b; Tung et al., 2018). The k-dimensional tree approach and Fast Marching are the two standard practices for extracting discontinuities on CloudCompare (Garcia-Luna et al., 2019). Both methods are less effective because the slope in this study area covers the highly weathered area. The COMPASS Plugin on CloudCompare is the best solution to overcome this problem.

\subsection{COMPASS Plugin}

The COMPASS plugin is a structural geological toolset for modeling and interpreting virtual outcrops. This tool combines a flexible data format for organizing geological interpretation with a set of simple and computer-assisted digitization and measuring capabilities. The instrument is divided into two modes: Map Mode, which is used to denote geological units, and Compass Mode, which is utilized to determine orientations and thicknesses. In this study, a plane is fitted to each trace (using least squares) when it is finalized (green tick or space key), 
providing an estimate of the structural orientation. In some situations, the best-fit plane does not provide a robust estimate of the structural orientation, particularly in the low relief. Planes derived from traces that are colinear or within $10^{\circ}$ of the average surface orientations along the trace are used to prevent these issues (if point normals have been calculated). Automatic plane fitting can be enabled/disabled (it is disabled by default) in the algorithm menu (settings icon), or the shift key is pressed when accepting the trace. Plane orientations are expressed using the dip/dip direction convention. The trace tool in COMPASS plugin allows the estimation of a structure or contact's orientation based on its intersection with a non-flat surface. It uses a leastcost path algorithm to "follow" these intersection traces along the surface between user defined start and end points and calculates the best fit plane to estimate the orientation (Fig. 12). The results of this tool depend on the cost function used by the least-cost path algorithm. When using this tool, it is important to note that its performance (i.e., speed) scales with trace length. Hence, it can be used with large point clouds if trace lengths are kept small (although long traces can be quickly digitized as multiple segments). Asking the tool to find long traces may result in system crashes (Compass (Plugin) - CloudCompareWiki, n.d.).

The Compass plugin orientation is verified using manual field mapping (Fig. 13) to replace the facet method. Approximately 23 discontinuity orientations were collected for manual mapping and 58 discontinuity orientations for this study. The example data collection from COMPASS plugin for study area is illustrated in Fig. 14 and Table 2.

Table 2 Example data collection for dip and dip direction from COMPASS Plugin and verification with manual measurement using geological compass

\begin{tabular}{ccccc}
\hline \multirow{2}{*}{ Joint ID } & \multicolumn{2}{c}{ Compass Plugin, Cloud Compare } & \multicolumn{2}{c}{ Geological Compass } \\
\cline { 2 - 5 } & Dip & Dip Direction & Dip & Dip Direction \\
\hline Slope Face & 36 & 45 & 35 & 40 \\
J12 & 64 & 32 & 61 & 29 \\
J13 & 76 & 47 & 78 & 45 \\
J14 & 88 & 44 & 82 & 41 \\
J15 & 64 & 41 & 63 & 42 \\
J16 & 69 & 55 & 65 & 51 \\
J17 & 77 & 49 & 73 & 44 \\
J18 & 61 & 57 & 63 & 54 \\
J19 & 67 & 47 & 62 & 44 \\
\hline
\end{tabular}

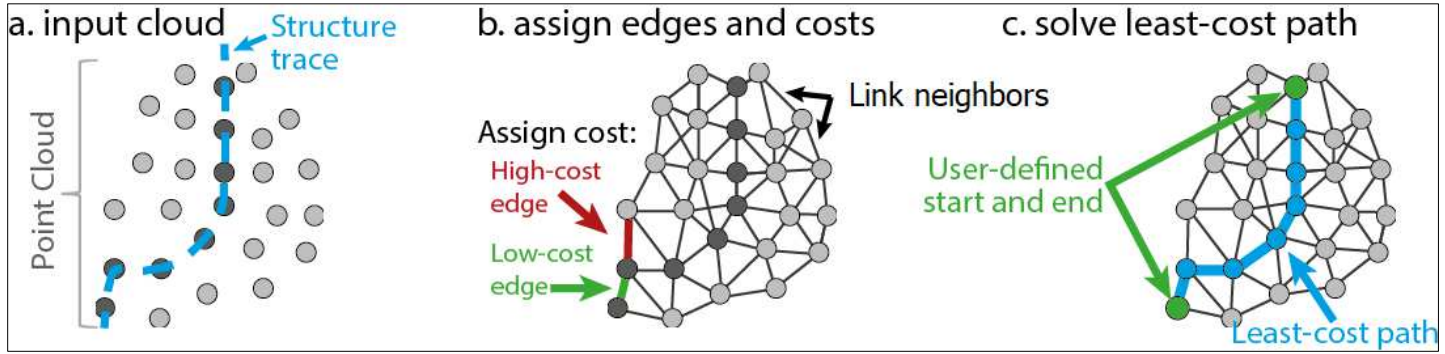

Fig. 12 Schematic showing the least-cost path approach to trace detection in a point cloud implemented in the compass plugin (Compass (Plugin) - CloudCompareWiki, n.d.) 


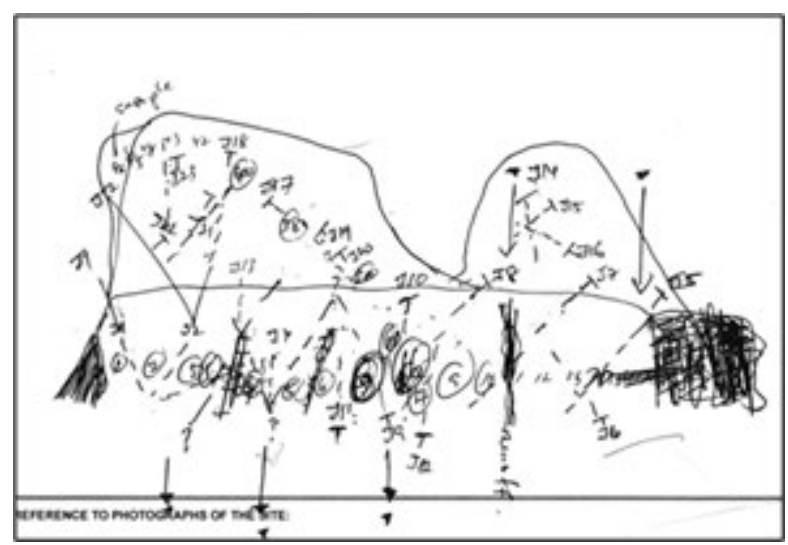

Fig. 13 Manual geological sketch of slope in Lebuhraya Kuala Kubu Bharu-Teranum-Raub showing a variation of dip and dip directions and 23 critical planes

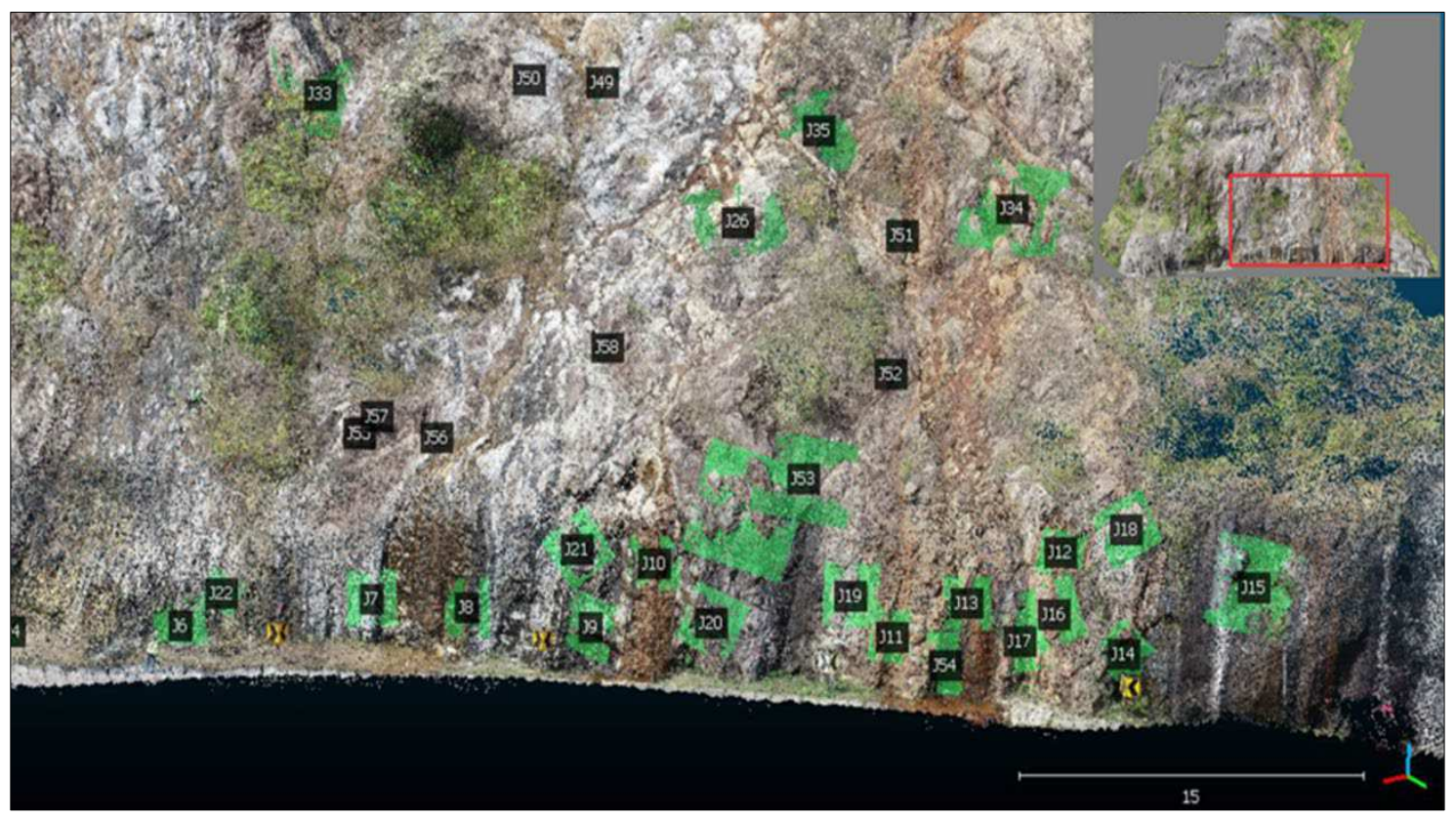

Fig. 14 Example of Compass plugin's discontinuity reading for Lebuhraya Kubu BharuTeranum-Raub

\section{Geomechanical Testing}

In this study, the image analysis technique will be compared with geomechanical testing to verify the outcomes. This study focused on 50 points of measurements of the rock slope of Lebuhraya Kubu Bharu-Teranum-Raub. The geomechanical testing included in this study is uniaxial compressive strength (UCS) from N-type Schmidt rebound hammer, laboratory UCS, point load test, and ultrasonic pulse velocity (UPV). The number of samples is summarized in Table 3. The methodology for the index properties is as follows: ASTM D5731-08, 2008; Franklin, 1985, and the samples tested are cylindrical cores with a width (D) to height (H) ratio of 0.3 DHD. The point load strength is converted to UCS using the correlation UCS $=\mathrm{C} \times$ Is 50 (Franklin, 1985). This study tested four (4) granitic samples from the study area for the corrected point load strength index, Is 50 , using the D550 machine model. A UCS was correlated to the color index ( $\mathrm{a}^{*}$ and $\mathrm{b}^{*}$ values) and image analysis zoning to validate the results. The test is carried out on an intact rock at the laboratory with no discontinuities and yield data on the rock material properties. The height to diameter $r$ atio of $2: 1$ is a minimum for cylinders, 
according to the International Society for Rock Mechanics (Fig. 15) (ASTM, 2014; ISRM, 1977). The velocity of the P-waves (Vp) in the UPV test was determined using the time-offlight technique at $1 \mathrm{MHz}$ (ISRM, 1978).

Table 3 Summary of the number of samples for intact rock test

\begin{tabular}{ccc}
\hline Geomechanical Testing & No of Samples & Remarks \\
\hline UCS Schmidt & 50 & Point of measurement \\
UCS Laboratory & 4 & $\mathrm{C} 12, \mathrm{C} 14, \mathrm{C} 15$, and C13 \\
UCS Point load & 4 & $\mathrm{C} 18, \mathrm{C} 19, \mathrm{C} 20$, and C21 (irregular) \\
UPV & 4 & $\mathrm{C} 19, \mathrm{C} 20, \mathrm{C} 21$, and C22 (irregular) \\
\hline
\end{tabular}

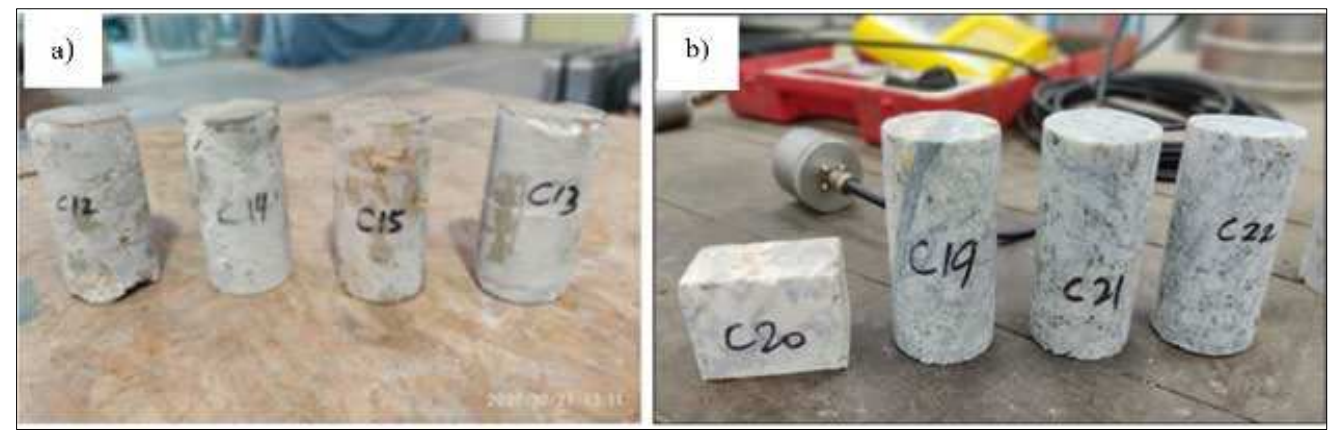

Fig. 15 Samples prepare for a) UCS Test and b) UPV

\section{Results And Discussion}

\subsection{Quantitative Weathering Assessment using CIELAB Color Space}

The $\mathrm{L}^{*}, \mathrm{a}^{*}$, and $\mathrm{b}^{*}$ values from the CIELAB color space demonstrate a positive correlation with weathering grades. The findings (Fig. 14) show that the rock is more weathered when the $a^{*}$ and $b^{*}$ values are higher than those with lower values. Similar results prove the hypothesis stated in predicting the tunnel face weathering grades (Tobe et al., 2020). The CIELAB values were tabulated for each of the 50 points of measurement on this rock slope (Fig. 16). Table 4 summarizes the data on an average basis. The results show that the $\mathrm{a}^{*}$ value ranged from 5 to 35 with an average of 18 , while the $b^{*}$ value ranged from 10 to 50 with an average of 30 . The correlation of the $a^{*}$ and $b^{*}$ values show significant results with $R 2=0.9027$, which was nearest to one. The positive $\mathrm{a}^{*}$ value in the CIELAB color space represents an object's redness (Fig. 16). The results quantify the change in color of the rock slope from unweathered to highly weathered rock. These findings are consistent with those of Tobe et al. (2020) who found that heavily weathered rock samples had higher $a^{*}$ and $b^{*}$ values than unweathered rock. The study's findings were compared with a digital photo taken on site (Table 5), and a correlation with weathering description shows a significant value. The selected samples from 50 points of measurements in the study area demonstrate a reliable assessment, increasing the level of weathering from slightly weathered (strong rock) to highly weathered (weak rock) with the increase in the $a^{*}$ and $b^{*}$ values. This result suggests that it is a feasible and reliable method for quantifying weathering using the CIELAB color space. Given that color is a primary indicator of weathering rock, digital photographs can be an effective tool for comparing the value obtained with a colorimeter. 
Table 4 Average of the 50 point of measurement (L, $a^{*}$, and $\left.b^{*}\right)$ values for the study area

\begin{tabular}{lccc}
\hline Statistical Data & $\mathrm{L}$ & $\mathrm{a}^{*}$ & $\mathrm{~b}^{*}$ \\
\hline Average & 52 & 18 & 30 \\
Median & 51 & 16 & 28 \\
Standard deviation & 18.32 & 7.51 & 10.24 \\
\hline
\end{tabular}

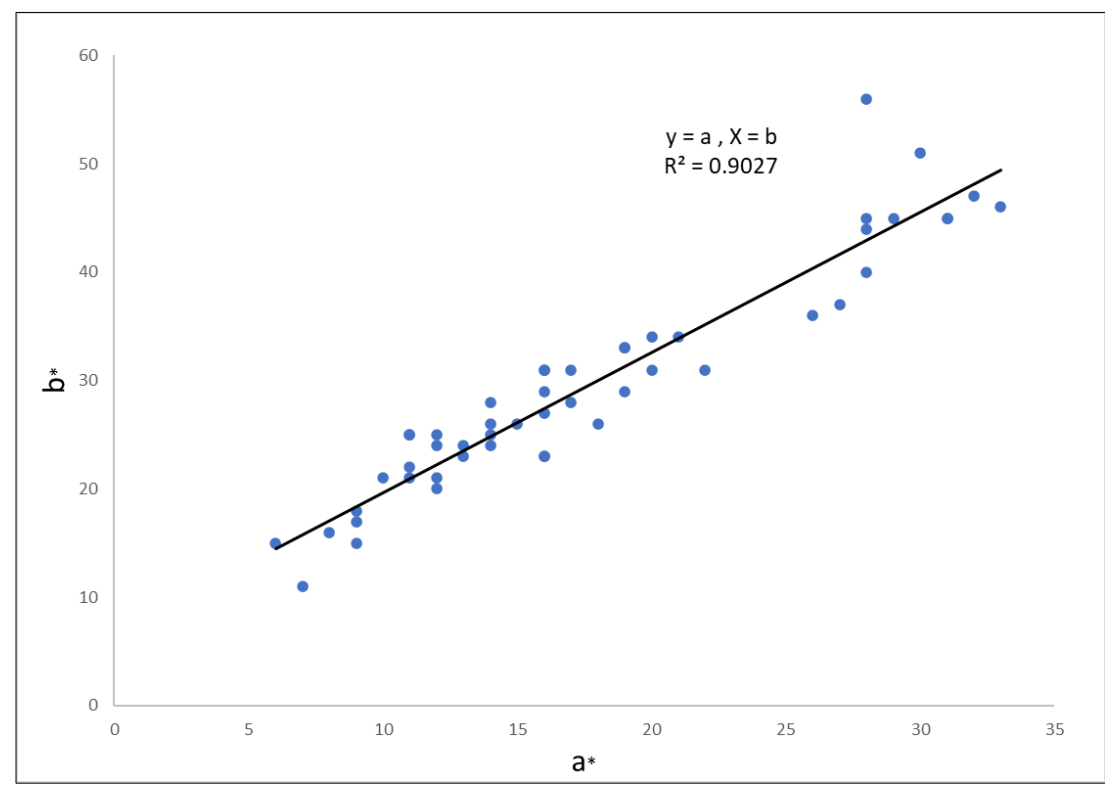

Fig. 16 Correlation of $a *$ to $b *$ of the study area

Table 5 Selected results for the $\mathrm{L}^{*}, \mathrm{a}^{*}$, and $\mathrm{b}^{*}$ values referred to the weathering description correlation

\begin{tabular}{|c|c|c|c|c|c|c|c|}
\hline \multirow{2}{*}{$\begin{array}{c}\text { Point } \\
\text { ID }\end{array}$} & \multicolumn{3}{|c|}{ Lab Value } & \multirow{2}{*}{$\begin{array}{l}\text { Schmidt } \\
\text { UCS }\end{array}$} & \multirow[t]{2}{*}{ Photo } & \multirow{2}{*}{$\begin{array}{c}\text { Color } \\
\text { simulation }\end{array}$} & \multirow[t]{2}{*}{ Description } \\
\hline & $\mathrm{L}$ & $\mathrm{a}$ & $\mathrm{B}$ & & & & \\
\hline 1 & 15 & 12 & 25 & 47.5 & & & $\begin{array}{l}\text { Medium-strong, small close fracture, } \\
\text { moderately weathered, and greenish- } \\
\text { gray color }\end{array}$ \\
\hline 3 & 33 & 6 & 15 & 31 & & & $\begin{array}{l}\text { Weak, small to medium close } \\
\text { fracture and joints, slightly } \\
\text { weathered, and whitish-gray color }\end{array}$ \\
\hline 5 & 48 & 11 & 21 & 58.5 & & & $\begin{array}{l}\text { Strong, small close fracture and } \\
\text { joints, moderately weathered, and } \\
\text { yellowish-brown color }\end{array}$ \\
\hline 40 & 39 & 18 & 26 & 31 & & & $\begin{array}{l}\text { Medium weak, small to large-close } \\
\text { fracture and joints, moderately } \\
\text { weathered, and reddish yellowish- } \\
\text { brown color }\end{array}$ \\
\hline 41 & 38 & 12 & 20 & 29.5 & & & $\begin{array}{l}\text { Weak, small to large-close fracture } \\
\text { and joints, highly weathered, and } \\
\text { brownish grey color }\end{array}$ \\
\hline
\end{tabular}




\subsection{Quantitative Weathering Assessment using Image Analysis}

The finding illustrates some results of the image analysis method in quantitatively assessing the weathering grade. In Table 6 and Fig. 17, the color of the rock changes with the increase in the weathering grade. The orange and red colors indicate vegetation and are particularly noticeable near the crest area. At this zone, the rock is weathered, and the rock mass is loose. Granites are highly variable in thickness even at the outcrop scale (hence the differences in weathering extent between heavily jointed and massive granites); thus, the saprolite thickness may be highly variable. Rotational slides are common in the color zone red-orange, with debris slides in the yellowish zone. Green zoning with reddish-yellowish brown discoloration indicates that this zone has the possibility of rock rolling. Blue zoning has a similar possibility of failure as the green zone, which is influenced by rolling rocks because some rocks decomposed and/or disintegrates into the soil and have discontinuity on the slope surface. Blue zone is the second most prevalent colour, accounting for $23 \%$ of the total rock slope, indicating extensive discolouration on the granite masses. The texture of rock from medium to coarse grain when its moderately weathered also influenced rock to rolling. The black zoning represents the major area with $51 \%$ of the total rock slope. This percentage excludes shotcrete on the slope.. Green is the next color, containing $12 \%$ discoloration and rock that degrades into the soil. Yellow represents the residual soils found near certain types of vegetation. Accordingly, a combination of orange and red represents $8 \%$ of the total rock slope and is used to analyze the vegetation on the slope. This zone is composed of heavily weathered granite because of the exposure and water flow from the top of the slope. Fig. 17 shows that the left and right sides of the slope are severely weathered, ranging from grade IV to V. Meanwhile, the slope's center is slightly to moderately weathered, with grades II and III as observed in Figs. $17 \mathrm{a}$ and $17 \mathrm{~b}$. The most intriguing discovery we made was the correlation between weathering grade zoning and slope image analysis. The finding from image analysis (Fig. 17c) shows a more significant value compared with the manual observation.

Table 6 Interpretation and description of the image analysis of slope Lebuhraya Kuala Kubu Bharu-Teranum-Raub expressway

\begin{tabular}{|c|c|c|c|c|c|c|}
\hline Color & Interpretation & Description & $\begin{array}{c}\text { Weathering } \\
\text { Percentage } \\
(\%)\end{array}$ & $\begin{array}{l}\text { Rock } \\
\text { Grade }\end{array}$ & $\begin{array}{l}\text { Estimated } \\
\text { Schmidt } \\
\text { UCS }\end{array}$ & $\begin{array}{l}\text { Possibility of Rock } \\
\text { Failure }\end{array}$ \\
\hline & Vegetation & $\begin{array}{l}\text { Some vegetation on the } \\
\text { soil might cause loose } \\
\text { to very loose rock mass }\end{array}$ & 8 & R0 & $5-1$ & $\begin{array}{l}\text { Rotational slides } \\
\text { and slumps }\end{array}$ \\
\hline & $\begin{array}{l}\text { Yellowish-brown } \\
\text { (residual soils) }\end{array}$ & $\begin{array}{l}\text { Some discoloration and } \\
\text { integration of soils }\end{array}$ & 7 & $\begin{array}{l}\mathrm{R} 1- \\
\mathrm{R} 2\end{array}$ & $20-5$ & Debris slides \\
\hline & $\begin{array}{l}\text { Reddish-yellowish } \\
\text { brown (iron- } \\
\text { stained and } \\
\text { seepage) }\end{array}$ & $\begin{array}{l}\text { Some discoloration and } \\
\text { rock decomposed } \\
\text { and/or disintegrated } \\
\text { into the soil }\end{array}$ & 12 & R3 & $35-20$ & Rolling rocks \\
\hline & $\begin{array}{l}\text { Greyish brown } \\
\text { (medium to coarse } \\
\text { grain) }\end{array}$ & $\begin{array}{l}\text { Some discoloration on } \\
\text { the rock masses and } \\
\text { discontinuity of the } \\
\text { surfaces }\end{array}$ & 23 & R4 & $50-35$ & Rolling rocks \\
\hline & Dark gray to black & $\begin{array}{l}\text { Discoloration on the } \\
\text { major discontinuities } \\
\text { of the surface }\end{array}$ & 51 & $\begin{array}{l}\text { R4- } \\
\text { R5 }\end{array}$ & $100-50$ & $\begin{array}{l}\text { Rockfalls, } \\
\text { rockslides, block } \\
\text { glides, and slide } \\
\text { over sheeting } \\
\text { surfaces }\end{array}$ \\
\hline
\end{tabular}




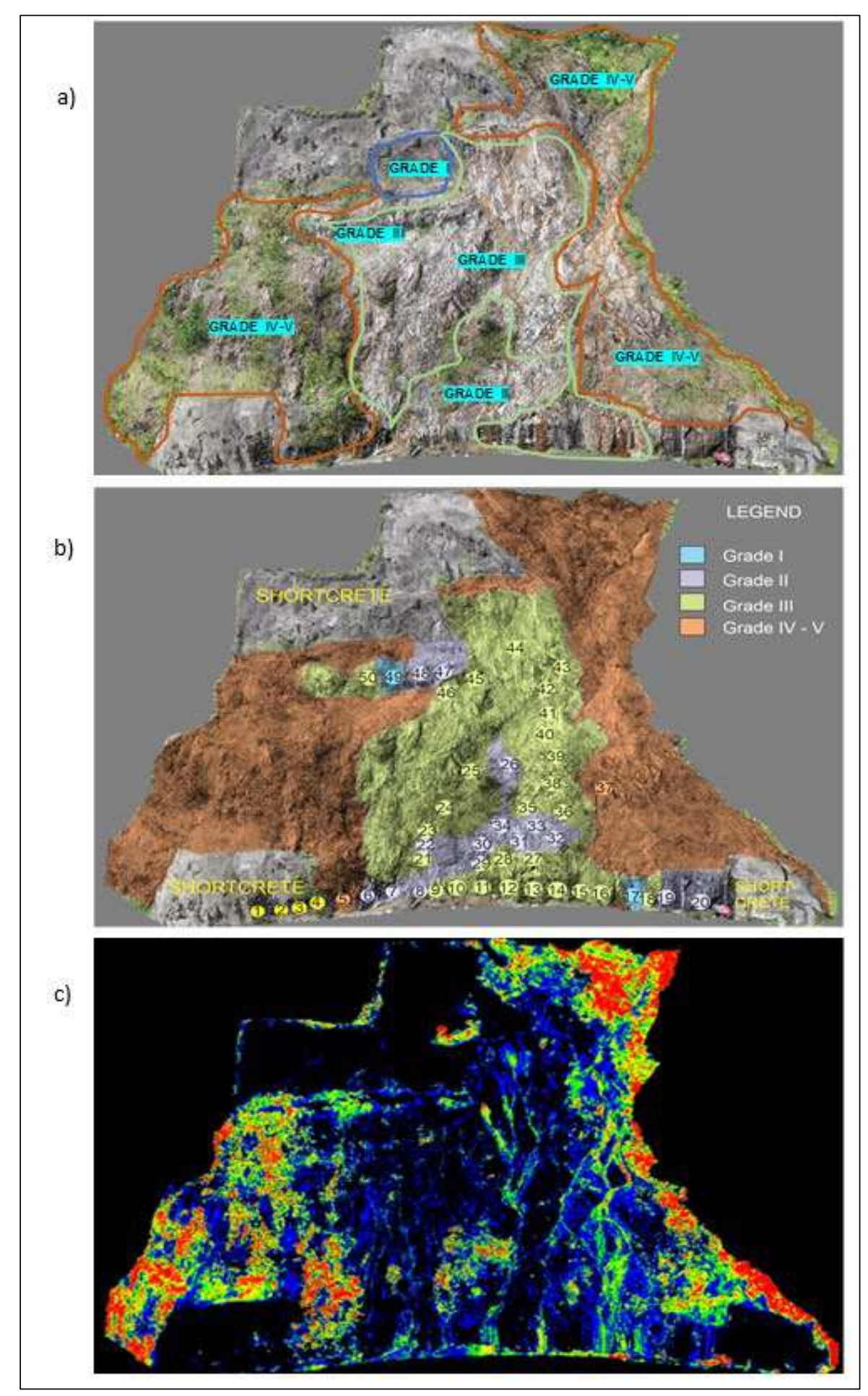

Fig. 17 Weathering grade zoning and image analysis of Lebuhraya Kuala Kubu Bharu Teranum - Raub route; a) and b) manual observation, c) image analysis observation

\subsection{Geological Structural Verification}

Based on the results (Fig. 18), the risk of planar sliding is $6.90 \%$ in the study region, with a critical joint set (JS) two risks of $12.5 \%$ and a flexural toppling failure risk of $1.72 \%$. In the study locations, the chance of wedge sliding is $5.51 \%$. The COMPASS tool from CloudCompare provides a good result for determining the rock discontinuity. The field mapping produced 23 visible discontinuity orientations. In Fig. 18, the granite slope in the 
study area is susceptible to flexural toppling failure, wedge sliding, and risk of planar sliding. Planar sliding at these study locations has a common trend whereby the failure planes are subparallel to the slope face, and the rock mass slides down along a relatively planar failure surface. The observed failure surfaces are overlain by slightly to completely weathered rock. The limitation of this study is that the extracted values from CloudCompare has a certain offset of $10^{\circ}$ or $10 \%$ from the actual reading on-site (Nagendran et al., 2019a; Tung et al., 2018). For instance, the extracted slope face orientations from COMPASS tool CloudCompare for the study area provides $36^{\circ} / 45^{\circ}$, while the manual mapping on-site produces $35^{\circ} / 40^{\circ}$ (Table 2 ). A slight difference of $1^{\circ}$ for the dip and $5^{\circ}$ dip directions was observed. The apparent difference is acceptable, and the offset of dip direction is caused by the misconception of the slope plan profile's point of view. The combination of UAV photogrammetry and field discontinuity data measurement overcomes the limitation in assessing the big scale slope face. Based on the results (Table 6), the rock slope can still fail due to geological structural failure; rolling, rockfalls, rockslides, block glides, and slide over sheeting surfaces, although the rock is considered strong (R4-R5). According to the image analysis, 51\% (black zone ) and 23\% (blue zone) shows the critical zone intent to slope failure because only this zone is a structurally controlled failure. The results from stereonet (Fig. 16) verify this statement. The blue and black color zoning can still slide with the stated type of failure. The findings demonstrate the potential of improving the technology for quantitative weathering assessment using CIELAB and image analysis. In the zoning image, the Schmidt hammer value is used to determine the weathering grade. With this correlation, the weathering results obtained through image analysis are more detailed than those manually obtained using the Schmidt hammer value. It is much easier to determine and verify which portion or area has been moderately or significantly weathered.

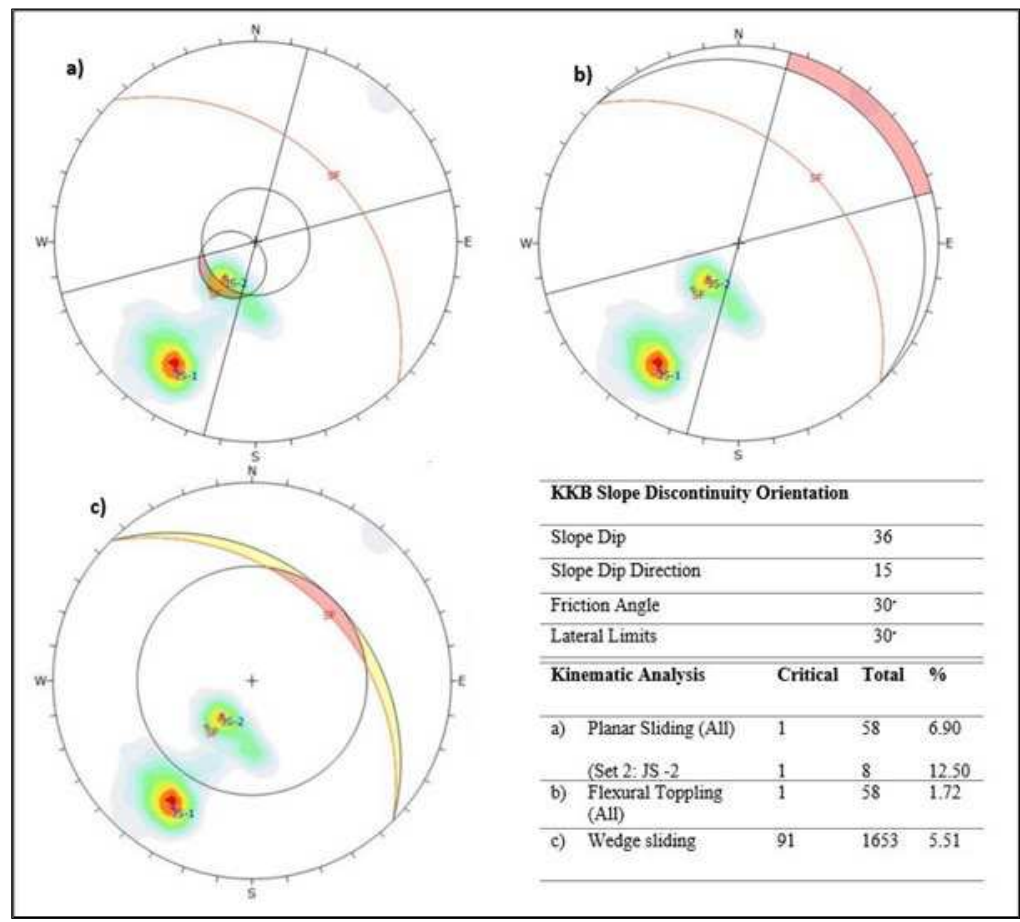

Fig. 18 Stereographic plots defining a) planar, b) toppling failure, and c) wedge failure mode

\subsection{Geomechanical Verification}

Table 7 illustrates that the rebound values of the UCS Schmidt hammer range from $100 \mathrm{MPa}$ to $105 \mathrm{MPa}$. The weathering of grade (II) shows positive trends, with values ranging from 54 $\mathrm{MPa}$ to $75.5 \mathrm{MPa}$ for the study areas. The weathering grade (III) indicates a strength range of 
28.5-49 MPa (Fig. 19). Given that grades (IV) and (V) are considerably low for Schmidt hammer, no UCS Schmidt hammer rebound values are tabulated for these weathering classifications. The finding is important to validate the results from the image analysis. According to the UCS Schmidt (Fig. 19), the laboratory results showed a positive trend. The grade classification for the study area is classified as medium-strong (R3-R4); hence, it is a strongly validated the image analysis technique results (Fig. 17). These relationships minimize the uncertainties of the UCS Schmidt hammer rebound values.

Table $7 \mathrm{Vp}$, UCS, and density of the granite sample from the KKB slope

\begin{tabular}{cccccc}
\hline $\begin{array}{c}\text { Compressional } \\
\text { Wave Velocity, Vp } \\
\text { ranges }(\mathrm{m} / \mathrm{s})\end{array}$ & $\begin{array}{c}\text { UCS } \\
\text { Schmidt } \\
(\mathrm{MPa})\end{array}$ & $\begin{array}{c}\text { UCS Lab } \\
(\mathrm{MPa})\end{array}$ & $\begin{array}{c}\text { UCS Point } \\
\text { Load } \\
(\mathrm{MPa})\end{array}$ & $\begin{array}{c}\text { Density } \\
\left(\mathrm{g} / \mathrm{cm}^{3}\right)\end{array}$ & $\begin{array}{c}\text { Average UCS } \\
(\mathrm{MPa}) / \text { Rock Grade } \\
\text { Classification }\end{array}$ \\
\hline $3700-4800$ & $100-105$ & $28-105$ & & $2.5-2.7$ & $\begin{array}{c}45.9 / \text { R3 Medium } \\
\text { Strong }\end{array}$ \\
\hline
\end{tabular}

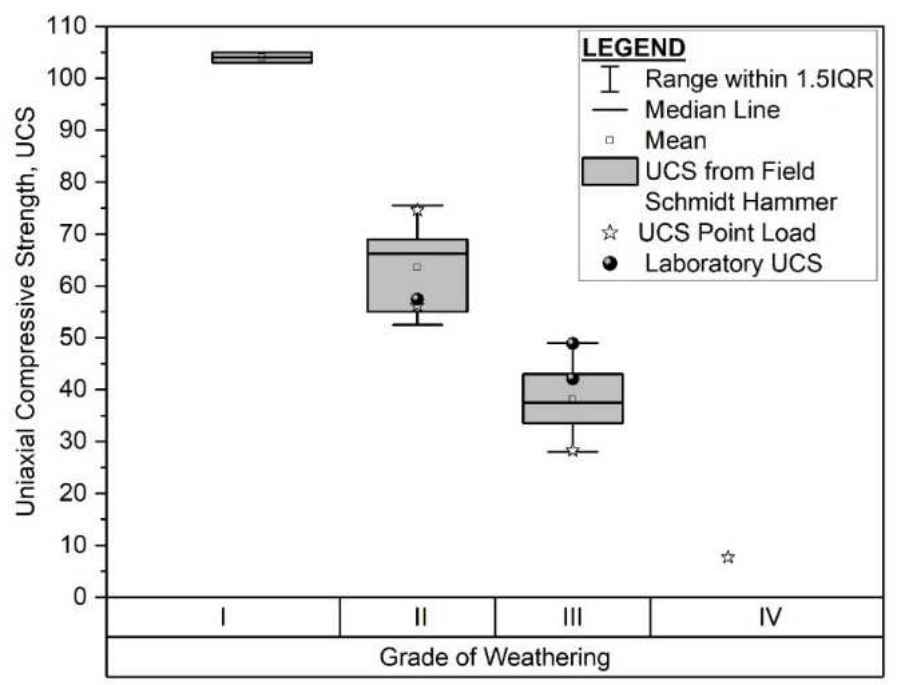

Fig. 19 Relationships between surface weathering, UCS Schmidt hammer rebound values, laboratory UCS, and UCS point load test from the study area

\subsection{Mineralogical Verification}

The analysis and results must be verified with their mineralogical properties. The thin granite samples TS18, TS19, TS20, TS21, and TS22 from the rock sample at the study area (Table 8) were used to generate a rock mineralogy evaluation, which was classified depending on the degree of weathering that the samples had experienced. The result demonstrates that the typical weathering grade of granite samples ranges from Grades III to IV, with Grade II samples found in some areas. According to the mineral evaluation on the study area, quartz, plagioclase and fragments of rock are $40 \%, 40 \%$, and $20 \%$ in TS18, respectively. TS19 is characterized by $50 \%$ quartz, $40 \%$ plagioclase, and $10 \%$ rock fragments. However, TS20 is characterized by $20 \%$ alkaline feldspar, 5\% hornblende-chlorite, 30\% quartz, and 45\% plagioclases. The rock fragments are difficult to see. TS2 1 is characterized by $30 \%$ quartz, $20 \%$ hornblende chloride, $40 \%$ plagioclase, and $20 \%$ rock fragments. Nonetheless, TS22 is distinguished by $40 \%$ quartz, $20 \%$ alkaline feldspar, 30\% plagioclase, and 10\% rock fragments. Chlorite change in hornblende granite, and the alteration in alkaline feldspar is caused by the weathering in the TS20 and T21 samples. The variation in the mineral assembly of granite also regulated surface 
weathering at the site. The change in quartz and other mineral products depends on the cooling variety of the volcanic rocks versus the crystal growth. The alteration of minerals associated with surface weathering is interpreted in different ways. Mineral alteration in granite occurs in certain minerals, such as alkaline feldspar, plagioclase, and hornblende. The plagioclase with epidote (whitish stripes) alteration occurs in sample TS19. Samples TS18, TS20, TS21, and TS22 show alterations in hornblende (light green) and alkali feldspar (light burn) with chlorite (rusty). The larger quartz rate in TS19 indicates a spike in UCS readings in laboratories and weathering grade (II). The low reading of the UCS load test indicates that the sample is heavily fractured (grade IV weathering).

The study significantly verified that the rock from the study area is categorized as a strong rock with weathering grades II and III. Meanwhile, the analysis from CIELAB and imaging technique justifies that range is similar. Granite exhibits weathering ranging from grade (I) to grade (III) as determined by the UCS Schmidt hammer rebound test. The range is adjusted on the basis of the laboratory UCS and UCS point load test results where the actual ranges become grade (II) to grade (IV) weathering. In granite samples, hornblende and alkaline feldspar minerals were altered by chlorite, and while plagioclase was altered by epidote. These findings confirm the progression of granite weathering from grade (II) to grade (IV).

Table 8 Selected thin section samples with their mineral compositions of Lebuhraya Kuala Kubu Bharu-Teranum-Raub

\begin{tabular}{|c|c|c|c|c|c|}
\hline \multirow{2}{*}{$\begin{array}{c}\text { Thin } \\
\text { Section ID }\end{array}$} & \multirow{2}{*}{$\begin{array}{c}\text { Rock } \\
\text { Type }\end{array}$} & \multirow{2}{*}{$\begin{array}{c}\begin{array}{c}\text { Weathering } \\
\text { Grade }\end{array} \\
\text { III }\end{array}$} & Thin Section Images & \multicolumn{2}{|c|}{ Mineral Composition (\%) } \\
\hline & & & & Quartz & 40 \\
\hline & & & & Alkali Feldspar & - \\
\hline & & & & Plagioclase & 40 \\
\hline & & & & Rock Fragments & 20 \\
\hline \multirow[t]{4}{*}{ TS19 } & Granite & III & & Quartz & 50 \\
\hline & & & & Alkali Felspar & - \\
\hline & & & & Plagioclase & 40 \\
\hline & & & & Rock Fragments & 10 \\
\hline \multirow[t]{4}{*}{ TS20 } & Granite & III & & Quartz & 30 \\
\hline & & & & Alkali Feldspar & 20 \\
\hline & & & & Plagioclase & 45 \\
\hline & & & & Hornblende Chloride & 5 \\
\hline \multirow[t]{4}{*}{ TS21 } & Granite & II & & Quartz & 30 \\
\hline & & & & Hornblende-Chloride & 20 \\
\hline & & & & Plagioclase & 40 \\
\hline & & & & Rock Fragments & 20 \\
\hline \multirow[t]{3}{*}{ TS22 } & Granite & II & & Quartz & 40 \\
\hline & & & & Alkali Feldspar & 20 \\
\hline & & & & Plagioclase & 30 \\
\hline
\end{tabular}




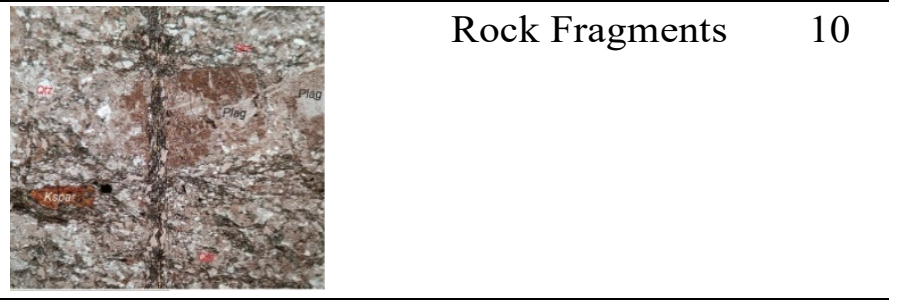

\section{Conclusion}

In summary, this slope mapping study accomplished all its primary objectives in assessing the quantitative weathering assessment of rock slopes for the Lebuhraya Kuala Kubu BharuTeranum-Raub route. The Colorimeter test is one of the methods for quantifying weathering grade using the color variants from the CIELAB concept. JudGeo software's for image analysis generates a spectrum of colors that represents the degree of weathering based on the orthoimages generated from UAV photogrammetry. The sequence of red, orange, yellow, green, blue, and black represents the various degrees of weathering (grades VI to I). The granite on the study area exhibits an unusually high black color code, indicating that it is a strong rock. The general geology of the study areas demonstrates considerable variation in terms of rock formation. This notion is validated through the analytical geomechanical test and its geological structure. Apart from justifying the analysis of the weathering rock slope surface, this study emphasizes the relationship between the strength of intact rock assessments and surface weathering. This study is conducted to ensure the accuracy of the results and to reduce uncertainty. UCS and values obtained from Schmidt hammer rebound tests were compared with the standard weathering classification grade. The finding demonstrates the significant similarity in the ranges of UCS Schmidt hammer rebound values regardless of the rock type or location. The variation in weathering grade is directly related to the mineral composition and alteration of the mineral. The weathered granite eventually becomes significantly more permeable, accelerating the rate of weathering. Erosion agents utilize the disparity between unweathered and weathered rocks to ensure that the fracture patterns associated with crustal stress are closely represented in landform and topographic patterns independent of climatic conditions. The volcanic rock varies in texture and contains stable minerals that are less susceptible to weathering on the surface. The weathering grade in the imaging technique, which corresponds to the UCS Schmidt hammer rebound values, is grouped and classified using userdefined colors of blue, purple, green, and orange on the ortho-images. The color scheme indicates the degree of weathering, ranging from grade (I) to grade (V). The comparison of the color images generated by the JudGeo software demonstrates an acceptable trend in terms of color codes and their coverage areas. In comparison to UCS Schmidt, the JudGeo images provide a more precise grade of weathering classification. Schmidt's hammer is a point accumulator. This slope does not cover the top areas of rock slopes in the investigation due to technical limitations. The grade of weathering in the upper portion of the slope was not recorded, necessitating imagination when classifying the grade of weathering. This situation is unquestionably causing interpretation errors, which can be correctly verified only with the JudGeo software application in the imaging technique.

\section{Acknowledgement}

This study is funded by an AUNSEED-Net/JICA Project under the Alumni Program for Research on the topic 'Development of Quantitative Weathering Method Using Multi-Model Image Analysis Technique for Rock Slope Instability Assessment in Tropical Region' and the Centre of Excellence for Engineering \& Technology (CREaTE), JKR for their financial support 
for the fieldwork. The first author also would like to express gratitude to USM GRA assist for the first year financial support of PhD study.

\section{References}

Abad, S. V. A. N. K., Mohamad, E. T., Komoo, I., \& Kalatehjari, R. (2015). Assessment of weathering effects on rock mass structure. Jurnal Teknologi, 72(1), 71-75. https://doi.org/10.11113/jt.v72.2875

Agisoft, L. L. C., \& St Petersburg, R. (2016). Agisoft photoscan professional edition. AgiSoft $L L C$.

Amano, K., Xiao, K., Wuerger, S., \& Meyer, G. (2020). A colorimetric comparison of sunless with natural skin tan. PLoS ONE, 15 (12 December), 1-15. https://doi.org/10.1371/journal.pone.0233816

Astm D5731-08. (2008). Standard Test Method for Determination of the Point Load Strength Index of Rock and Application to Rock Strength Classifications. ASTM International, West Conshohocken, PA, 22(2), 51-60.

Bobina, T. S., \& Abaturova, I. v. (2020). Assessment of the degree of rock weathering and engineering-geological zoning. Engineering and Mining Geophysics 2020. https://doi.org/10.3997/2214-4609.202051135

Borrelli, L., Coniglio, S., Critelli, S., la Barbera, A., \& Gullà, G. (2016). Weathering grade in granitoid rocks: The San Giovanni in Fiore area (Calabria, Italy). Journal of Maps, 12(2), 260-275. https://doi.org/10.1080/17445647.2015.1010742

Buyer, A., Pischinger, G., \& Schubert, W. (2018). Image-based discontinuity identification: Bildgestützte Trennflächenidentifikation. Geomechanik Und Tunnelbau, 11(6), 693-700. https://doi.org/10.1002/geot.201800047

Chen, J., Zhang, D., Huang, H., Shadabfar, M., Zhou, M., \& Yang, T. (2020). Image-based segmentation and quantification of weak interlayers in rock tunnel face via deep learning. $\begin{array}{llll}\text { Automation in } & \text { Construction, } & 1203371 .\end{array}$ https://doi.org/10.1016/j.autcon.2020.103371

Cinko, U. O., \& Becerir, B. (2019). Dependence of colour difference formulae on regular changes of colour coordinates in CIELAB colour space. Industria Textila, 70(3), 248-254. https://doi.org/10.35530/IT.070.03.1525

Compass (plugin) - CloudCompareWiki. (n.d.). Retrieved November 6, 2020, from https://www.cloudcompare.org/doc/wiki/index.php?title=Compass_(plugin)

de Matias, J., de Sanjose, J. J., Lopez-Nicolas, G., Sagues, C., \& Guerrero, J. J. (2009). Photogrammetric methodology for the production of Geomorphologic maps: Application to the Veleta Rock Glacier (Sierra Nevada, Granada, Spain). Remote Sensing, 1(4). https://doi.org/10.3390/rs1040829

Dewez, T. J. B., Girardeau-Montaut, D., Allanic, C., \& Rohmer, J. (2016). Facets : A CloudCompare Plugin to Extract Geological Planes From Unstructed 3D Point Clouds. ISPRS - International Archives of the Photogrammetry, Remote Sensing and Spatial Information Sciences, XLI-B5, 799-804. https://doi.org/10.5194/isprs-archives-xli-b5799-2016

Franklin, J. A. (1985). Suggested method for determining point load strength. In International Journal of Rock Mechanics and Mining Sciences and (Vol. 22, Issue 2, pp. 51-60). https://doi.org/10.1016/0148-9062(85)92327-7

Garcia-Luna, R., Senent, S., Jurado-Pina, R., \& Jimenez, R. (2019). Structure from Motion photogrammetry to characterize underground rock masses: Experiences from two real tunnels. Tunnelling and Underground Space Technology, 83(December 2017), 262-273. https://doi.org/10.1016/j.tust.2018.09.026 
Ghiasi, V., Omar, H., \& Huat, B. K. (2009). A study of the weathering of the Seremban granite. Electronic Journal of Geotechnical Engineering, 14 D.

Gokay, M. K. (2018). Analyses of Rock Surface Colour Changes Due To Weathering. Selcuk University Journal of Engineering ,Science and Technology, 6(1), 1-13. https://doi.org/10.15317/scitech.2018.111

Goyena, R., \& Fallis, A. G. (2019). Visual appraisal of beef and its Relationship with the CIELab colour space. Journal of Chemical Information and Modeling, 53(9), 1689-1699.

Grad, M. E., Simu, G. M., Muntean, S. G., \& Ilia, G. (2013). Synthesis, characterization and colour determination using CIELAB colour space of stilbene dyes. Journal of the Iranian Chemical Society, 10(4), 807-816. https://doi.org/10.1007/s13738-012-0216-y

Grotzinger, J., Jordan, T. H., Press, F., \& Siever, R. (2009). Understanding Earth (Looseleaf). W. H. Freeman. https://books.google.co.uk/books?id=rATVRwAACAAJ

ISO - ISO/CIE 11664-4:2019 - Colorimetry - Part 4: CIE $1976 L^{*} a * b *$ colour space. (n.d.). Retrieved July 29, 2021, from https://www.iso.org/standard/74166.html

ISRM. (1977). Suggested Methods for Determining the Uniaxial Compressive Strength and Deformability of Rock Materials. International Society for Rock Mechanics, December, $0-3$.

ISRM. (1978). Suggested methods for determining sound velocity. International Journal of Rock Mechanics and Mining Sciences \& Geomechanics Abstracts, 15(5), A100. https://doi.org/10.1016/0148-9062(78)91013-6

Jasin, B. (2013). Chert blocks in Bentong-Raub Suture Zone: A heritage of palaeo-tethys.

Jasin, B., \& Harun, Z. (2011a). Radiolarian biostratigraphy of Peninsular Malaysia - An update. Bulletin of the Geological Society of Malaysia, 57. https://doi.org/10.7186/bgsm57201105

Jasin, B., \& Harun, Z. (2011b). Radiolarian biostratigraphy of Peninsular Malaysia - An update. Bulletin of the Geological Society of Malaysia, 57, 27-38. https://doi.org/10.7186/bgsm57201105

ju, M., ka, D., \& Rohil, Dr. H. (2014). Real Time Hand Gesture Recognition Using CIELab Colour Space Model. International Journal of Computer \& Organization Trends, 5(1), 3139. https://doi.org/10.14445/22492593/ijcot-v5p308

Kemp, D. B. (2014). Colorimetric characterisation of flatbed scanners for rock/sediment imaging. Computers and Geosciences, 67, 69-74. https://doi.org/10.1016/j.cageo.2014.03.002

Kim, D. H. (2015). The ULAB colour space. Color Research and Application, 40(1), 17-29. https://doi.org/10.1002/col.21854

Kim, D. H., Balasubramaniam, A. S., \& Gratchev, I. (2018). Application of photogrammetry and image analysis for rock slope investigation. Geotechnical Engineering.

Kong, D., Saroglou, C., Wu, F., Sha, P., \& Li, B. (2021). Development and application of UAV-SfM photogrammetry for quantitative characterization of rock mass discontinuities. International Journal of Rock Mechanics and Mining Sciences, 141. https://doi.org/10.1016/j.ijrmms.2021.104729

Lovisolo, L. (2011). Improvement of Objective Image Quality Evaluation Applying Colour Differences in the CIELAB Colour Space. International Journal of Image Processing, 5, 236-243.

Luo, J. Y., Xu, Z. M., Ren, Z., Wang, K., Gao, H. Y., Yang, K., Tang, Y. J., \& Tian, L. (2020). Quantitative assessment of weathering degree of the Touzhai rock-avalanche deposit in Southwest China. Geomorphology, 359. https://doi.org/10.1016/j.geomorph.2020.107162

Metcalfe, I. (2000). The Bentong-Raub Suture Zone. Journal of Asian Earth Sciences, 18(6), 691-712.

Metcalfe, I. (2013). Tectonic evolution of the Malay Peninsula. Journal of Asian Earth Sciences, 76, 195-213. https://doi.org/10.1016/j.jseaes.2012.12.011 
Mohan, A., \& Poobal, S. (2018). Crack detection using image processing: A critical review and analysis. Alexandria Engineering Journal, 57(2), 787-798. https://doi.org/10.1016/j.aej.2017.01.020

Mohebbi, M., Fatehi Marji, M., \& Gholamnejad, J. (2017). Rock mass structural data analysis using image processing techniques (Case study: Choghart iron ore mine northern slopes). Journal of Mining and Environment, 8(1), 61-74. https://doi.org/10.22044/jme.2016.629

Moses, C., Robinson, D., \& Barlow, J. (2014). Methods for measuring rock surface weathering and erosion: A critical review. In Earth-Science Reviews (Vol. 135, pp. 141-161). Elsevier. https://doi.org/10.1016/j.earscirev.2014.04.006

Nagendran, S. K., Ismail, M. A. M., \& Tung, W. Y. (2019a). Integration of UAV photogrammetry and kinematic analysis for rock slope stability assessment. Bulletin of the Geological Society of Malaysia, 2019(67), 117-123. https://doi.org/10.7186/bgsm67201913

Nagendran, S. K., Ismail, M. A. M., \& Tung, W. Y. (2019b). Photogrammetry approach on geological plane extraction using cloudcompare FACET plugin and scanline survey. Bulletin of the Geological Society of Malaysia, 68, 151-158. https://doi.org/10.7186/bgsm68201916

Ohta, N., \& Robertson, A. R. (2005). Colorimetry Colorimetry: Fundamentals and Applications.

Outal, S., Jeulin, D., \& Schleifer, J. (2008). A new method for estimating the 3D sizedistribution-curve of fragmented rocks out of 2D images. Image Analysis and Stereology. https://doi.org/10.5566/ias.v27.p97-105

Park, J., \& Kim, K. (2019). Quantification of rock mass weathering using spectral imaging. Journal of the Southern African Institute of Mining and Metallurgy, 119(12), 1039-1046. https://doi.org/10.17159/2411-9717/708/2019

Planetary, E., \& Congress, S. (2014). Colorimetric analysis of rocks powders helping for the calibration of Close-up Imager (CLUPI) of the ExoMars mission. 9, 1-2.

Roy Choudhury, A. K. (2015a). Colour-difference assessment. In Principles of Colour and Appearance Measurement (Vol. 2). Woodhead Publishing Limited. https://doi.org/10.1533/9781782423881.55

Roy Choudhury, A. K. (2015b). Colour-difference assessment. In Principles of Colour and Appearance Measurement. https://doi.org/10.1533/9781782423881.55

Salvini, R., Vanneschi, C., Coggan, J. S., \& Mastrorocco, G. (2020). Evaluation of the Use of UAV Photogrammetry for Rock Discontinuity Roughness Characterization. Rock Mechanics and Rock Engineering, 53, 3699-3720. https://doi.org/10.1007/s00603-02002130-2

Shrivastava, D., Srivastava, K. C., Ganji, K. K., Alam, M. K., Zoubi, I. al, \& Sghaireen, M. G. (2021). Quantitative assessment of gingival inflammation in patients undergoing nonsurgical periodontal therapy using photometric CIELab analysis. BioMed Research International, 2021(March). https://doi.org/10.1155/2021/6615603

Spiller, F. C. P. (2002). Radiolarian biostratigraphy of Peninsular Malaysia and implications for regional palaeotectonics and palaeogeography. Palaeontographica, Abteilung A: Palaozoologie - Stratigraphie, 266(1-3), 1-91.

Sun, H., Belhaj, H., Tao, G., Vega, S., \& Liu, L. (2019). Rock properties evaluation for carbonate reservoir characterization with multi-scale digital rock images. Journal of Petroleum Science and Engineering, 175(December 2018), 654-664. https://doi.org/10.1016/j.petrol.2018.12.075

Tan, X., Konietzky, H., \& Chen, W. (2016). Numerical Simulation of Heterogeneous Rock Using Discrete Element Model Based on Digital Image Processing. Rock Mechanics and Rock Engineering. https://doi.org/10.1007/s00603-016-1030-0 
Thuro, K., Plinninger, R. J., \& Spaun, G. (2002). Drilling, Blasting and Cutting-Is It Possible to Quantify Geological Parameters Relating to Excavatability? In Engineering Geology for Developing Countries-Proceedings of 9th Congress of the International Association for Engineering Ge, September.

Thwaites, A., Wingfield, C., Wieser, E., Soltan, A., Marslen-Wilson, W. D., \& Nimmo-Smith, I. (2018). Entrainment to the CIECAM02 and CIELAB colour appearance models in the human cortex. Vision Research, 145(March), 1-10. https://doi.org/10.1016/j.visres.2018.01.011

Tobe, H., Miyajima, Y., Shirasagi, S., \& Yamamoto, T. (2020). A new method for predicting of rock fall from the tunnel face. Rock Mechanics for Natural Resources and Infrastructure Development- Proceedings of the 14th International Congress on Rock Mechanics and Rock Engineering, ISRM 2019, 1761-1768.

Tobe, H., Miyajima, Y., Shirasagi, S., Yamamoto, T., \& Kawabata, J. (2018). A rapid image analyzing method for determining crack distribution and interval on tunnel faces. ISRM International Symposium - 10th Asian Rock Mechanics Symposium, ARMS 2018.

Tung, W. Y., Nagendran, S. K., \& Mohamad Ismail, M. A. (2018). 3D rock slope data acquisition by photogrammetry approach and extraction of geological planes using FACET plugin in CloudCompare. IOP Conference Series: Earth and Environmental Science, 169(1), 12051. https://doi.org/10.1088/1755-1315/169/1/012051

Villarreal J, C. A., Rojas D, J. D., \& Ríos R, C. A. (2020). 3D digital outcrop modelling of the Lower Cretaceous Los Santos formation sandstones, Mesa de Los Santos region (Colombia): Implications for structural analysis. Journal of Structural Geology, 141(September). https://doi.org/10.1016/j.jsg.2020.104214

Ye, Z., Xu, Q., Liu, Q., Dong, X., Wang, X., \& Ning, H. (2020). Application of Unmanned Aerial Vehicle Oblique Photogrammetry to Investigation of High Slope Rock Structure. Wuhan Daxue Xuebao (Xinxi Kexue Ban)/Geomatics and Information Science of Wuhan University, 45(11). https://doi.org/10.13203/j.whugis20200077

Yeerken, Y. (2017). Applicability of the CIELAB and CIEDE2000 Formulae for Detection of Colour Changes in Colour-Changeable Chewing Gum for Evaluating Masticatory Function. Journal of Clinical and Diagnostic Research, 119-123. https://doi.org/10.7860/jcdr/2017/23950.9754

Zekkos, D., Greenwood, W., Lynch, J. P., Professor, A., Lynch, J., Athanasopoulos-Zekkos, A., \& Clark, M. (2018). Lessons Learned from The Application of UAV-Enabled Structure-From-Motion Photogrammetry in Geotechnical Engineering STructural stABiLity and risk assEssment-STABLE View project Behaviour of anisotropic rocks and rockmasses View project Lessons Learned fr. International Journal of Geoengineering Case Histories $\mathbb{C}$, 4, 254. https://doi.org/10.4417/IJGCH-04-04-03 


\section{Supplementary Files}

This is a list of supplementary files associated with this preprint. Click to download.

- Additionallnformationabvalue.xIsx 